\title{
Modern Approach to Delivery Coolants, Lubricants and Antiadhesives in the Environmentally Friendly Grinding Processes
}

\author{
Krzysztof Nadolny $^{1}$ D $\cdot$ Seweryn Kieraś ${ }^{2} \cdot$ Paweł Sutowski $^{1}$
}

Received: 18 June 2020 / Revised: 1 September 2020 / Accepted: 7 September 2020 / Published online: 21 September 2020

(c) The Author(s) 2020

\begin{abstract}
Control of thermal conditions in the grinding zone is possible through effective delivery of substances with cooling, lubricating and antiadhesive properties during the machining process. In addition to the benefits of coolants, however, a number of economic and ecological problems arise, which include the costs of purchase, use and maintenance as well as the environmental impact of its disposal. These negative aspects of the use of cooling and lubricating liquids have contributed to the modern trend of minimizing their output in machining processes, including grinding. This article presents comprehensive characteristics of knowledge in the field of liquids, gases and solids with cooling, lubricating and antiadhesive properties. The author's original classification of cooling and lubricating agents by their physical state was proposed and a complete list of known modern environmentally friendly methods of cooling and lubrication of the grinding zone was presented. In order to highlight their beneficial features, the background of conventional methods of delivery coolants, lubricants and antiadhesives to the grinding zone used for years were also characterised. A comprehensive list of all known methods of cooling and lubrication of the grinding zone classified according to the physical state of the delivered medium with a clear separation of hybrid methods consisting in simultaneous delivery of many cooling and lubricating agents was described in the summary. The article concludes with the characteristics of directions of further development in the field of cooling and lubrication of the grinding zone.
\end{abstract}

Keywords Cooling liquids $\cdot$ Lubricants $\cdot$ Cooling gases $\cdot$ Cooling methods $\cdot$ Environmentally friendly grinding

\begin{tabular}{|c|c|c|c|}
\hline \multicolumn{2}{|c|}{ List of Symbols } & $n_{s}$ & Grinding wheel rotational speed, rpm \\
\hline \multirow[t]{2}{*}{$a$} & Total working engagement (total machining & $n_{w}$ & Workpiece rotational speed, $\mathrm{rpm}$ \\
\hline & allowance), $\mathrm{mm}$ & $Q$ & Flow rate, $\mathrm{L} / \mathrm{min}$ \\
\hline \multirow[t]{2}{*}{$a_{e}$} & Working engagement (machining allowance), & $Q_{C L L}$ & Cooling and lubricating liquid flow rate, $\mathrm{L} / \mathrm{min}$ \\
\hline & $\mathrm{mm}$ & $Q_{w}$ & Material removal rate, $\mathrm{mm}^{3} / \mathrm{s}$ \\
\hline$F_{c}$ & Grinding force, $\mathrm{N}$ & $Q_{w}^{\prime}$ & Specific material removal rate, $\mathrm{mm}^{3} / \mathrm{s} \mathrm{mm}$ \\
\hline$F_{c}^{\prime}$ & Specific grinding force, $\mathrm{N} / \mathrm{mm}$ & $P$ & Grinding power, W \\
\hline \multirow{2}{*}{$\begin{array}{l}F_{n} \\
F_{t}\end{array}$} & Normal component of grinding force, $\mathrm{N}$ & $R a$ & Arithmetic mean deviation of the workpiece \\
\hline & Tangential component of grinding force, $\mathrm{N}$ & & roughness profile, $\mu \mathrm{m}$ \\
\hline$G$ & Grinding ratio $G=V_{w} / V_{s}, \mathrm{~mm}^{3} / \mathrm{mm}^{3}$ & $R t$ & $\begin{array}{l}\text { Total height of the roughness profile within a } \\
\text { sampling length, } \mu \mathrm{m}\end{array}$ \\
\hline & & $R z$ & Maximum height of the roughness profile \\
\hline \multirow{5}{*}{$凶$} & Krzysztof Nadolny & & within a sampling length, $\mu \mathrm{m}$ \\
\hline & Isztof.nadolny@t & $t_{s}$ & Grinding time, $\mathrm{s}$ \\
\hline & Seweryn Kieraś & $V_{s}$ & Grinding wheel volumetric wear, $\mathrm{mm}^{3}$ \\
\hline & seweryn.kieras@wartsila.com & $V_{w}$ & Workpiece volumetric wear, $\mathrm{mm}^{3}$ \\
\hline & $\begin{array}{l}\text { Paweł Sutowski } \\
\text { pawel.sutowski@tu.koszalin.pl }\end{array}$ & $v_{C C L}$ & $\begin{array}{l}\text { Cooling and lubricating liquid flow velocity, } \\
\mathrm{m} / \mathrm{s}\end{array}$ \\
\hline \multirow[t]{3}{*}{1} & Department of Production Engineering, Faculty & $v_{f a}$ & Axial table feed speed, $\mathrm{mm} / \mathrm{s}$ \\
\hline & of Mechanical Engineering, Koszalin University & $v_{f t}$ & Tangential table feed speed, $\mathrm{mm} / \mathrm{s}$ \\
\hline & of Technology, Racławicka 15-17, 75-620 Koszalin, Poland & $v_{s}$ & Grinding wheel peripheral speed, $\mathrm{m} / \mathrm{s}$ \\
\hline 2 & Wartsila Poland Sp. z o.o, Łużycka 2, 81-537 Gdynia, Poland & $v_{w}$ & Workpiece peripheral speed, $\mathrm{m} / \mathrm{s}$ \\
\hline
\end{tabular}




\section{Greek Symbols}

$\alpha_{1} \quad$ Alignment angle of compressed cooled air supply line outlet no. $1,^{\circ}$

$\alpha_{2} \quad$ Alignment angle of compressed cooled air supply line outlet no. $2{ }^{\circ}$

$\Delta P \quad$ Grinding power gain, $\mathrm{W}$

$\Delta P_{a v} \quad$ Average grinding power gain, $\mathrm{W}$

$\sigma \quad$ Standard deviation

\section{Abbreviations}

$\begin{array}{ll}\text { AOE } & \text { Aqueous Oil Emulsions } \\ \text { CAG } & \text { Cold Air Gun }\end{array}$

CAMQL Cold Air Minimum Quantity Lubrication

CAOM Cold Air and Oil Mist

CCA Cooled Compressed Air

CFD Computational Fluid Dynamics

CG Cooling Gases

CLF Cooling And Lubricating Fluids

CLL Cooling And Lubricating Liquids

CNT Carbon Nano-Tubes

EP Extreme Pressure

GWAS Grinding Wheel Active Surface

$\mathrm{LN}_{2} \quad$ Liquid Nitrogen

MQC Minimum Quantity Cooling

MQCL Minimum Quantity Cooling Lubrication

MQL Minimum Quantity Lubrication

MRR Material Removal Rate

\section{Introduction}

Proper realization of the abrasive machining process requires careful consideration of thermal conditions in the grinding wheel-workpiece contact zone. The maximum grinding temperature is most important for the shaped structure of the surface layer of the workpiece as well as for the composite layer of the abrasive tool. Control of thermal conditions in the grinding zone is possible through effective delivery of substances with cooling, lubricating and antiadhesive properties during the machining process $[1,2]$.

Since intergranular space of the grinding wheel active surface (GWAS) is relatively small, and maintaining a high level of cutting ability requires it to be free and to support the transport of grinding products from the machining zone, most grinding processes use liquids, gases and solids with cooling, lubricating and antiadhesive properties. The most numerous group are cooling and lubricating liquids (CLL), which are mainly used to lubricate and cool the grinding zone in contact with the workpiece material to reduce the friction of blades with undefined geometry and often a negative rake angle. More precise cooling tasks in the grinding process can be presented as follows [3, 4]:
- forming a stable lubricant film that reduces friction between the abrasive grain and workpiece as well as between the bond and workpiece,

- cooling of the workpiece surface and the GWAS through heat transfer and heat dissipation,

- wetting and cleaning the grinding wheel,

- chip flushing from the grinding zone,

- corrosion protection of the grinder and the material being processed,

- preventing the growth of bacteria, foaming, etc.

As a result, the most important properties of coolants in abrasive machining include [3, 4]:

- lubricity,

- the cooling capacity,

- the ability to flush and wet out,

- pressure transfer capability (pressure capacity),

- anticorrosion,

- viscosity,

- resistance to aging,

- bactericide,

- the ability to emulsify,

- non-foaming,

- separation capacity and filterability,

- non-reactivity with metals, plastics and paints,

- the ability to regenerate,

- the smell,

- antitoxicity,

- non-degradable,

- indissolubility,

- non-flammable and not explosive.

Such a large number of different features is very difficult to obtain, therefore in practice many different coolants are used, the properties of which are adjusted individually to each machining case $[1,3]$. Apart from the type of liquid, gas or solid with cooling, lubricating or antiadhesive effect used, the quantity and method of delivery the coolant to the grinding zone have a decisive influence on the course and results of the grinding process.

The following terms have been introduced in this paper in order to clarify the nomenclature for the types of cooling, lubricating and antiadhesive agents used in grinding processes:

- cooling and lubricating fluids (CLF),

- cooling and lubricating liquids (CLL),

- cooling gases (CG),

- antiadhesives and lubricants in solid state.

The term cooling and lubricating fluids has been replacing the previously used term cooling and lubricating liquids 
in the literature for several years now due to the increasing use of gases for cooling the grinding zone-liquid nitrogen $\left(\mathrm{LN}_{2}\right)$ or compressed air. The word for these two groups of substances (liquids and gases) is a fluid, understood as any substance that can flow, i.e. it is characterized by great ease of changing the mutual position of individual elements even for small forces. A liquid in this sense is not only liquids and gases but also plasma and even mixtures of different physical phases such as foam, emulsion, slurry and paste. CLF is therefore a term that includes, in a meaningful way, cooling liquids as well as cooling gases, which are characterised in this work by the switchgear. It is also worth noting that so far in the literature such terms as grinding fluid, cooling liquid, coolant, lubricant are used interchangeably, which do not fully determine the physical state of the medium used.

In this article, an attempt has been made to organize the terminology and comprehensive characteristics of knowledge in the field of liquids, gases and solids with cooling, lubricating and antiadhesive properties. The author's original classification of cooling and lubricating agents by their physical state was proposed and a complete list of known pro-ecological methods of cooling and lubrication of the grinding zone was presented against the background of conventional methods of delivery coolants, lubricants and antiadhesives to the grinding zone used for years. The summary includes a comprehensive list of all known methods of cooling and lubrication of the grinding zone classified according to the physical state of the delivered medium with a clear separation of hybrid methods consisting in simultaneous delivery of many cooling and lubricating agents.

\section{Liquids, Gases and Solids with Cooling, Lubricating and Antiadhesive Properties}

\subsection{Cooling and Lubricating Liquids}

The basic criterion of CLL division is the presence of water in them [5]. The main components of CLL immiscible with water are mineral oils, which are characterized by excellent lubricating properties. Depending on the detailed specification, their kinematic viscosity at $40{ }^{\circ} \mathrm{C}$ is $20-60 \mathrm{~mm}^{2} / \mathrm{s}$. This is more than fifty times the viscosity of water. Moreover, mineral oils are characterized by anticorrosive properties and when used, there is no need to use fungicides or corrosion inhibitors to protect the machine tool and workpiece due to their sterile nature. CLL based on mineral oils sometimes require additional use of substances preventing surface foaming. Mineral oils have a lower cooling effect than water-based CLL. The thermal capacity of oils is about $1.95 \mathrm{~kJ} /(\mathrm{kg} \mathrm{K})$ and their thermal conductivity is about $0.13 \mathrm{~W} /(\mathrm{m} \mathrm{K})$ [5]. To improve lubricating properties of oils, extreme pressure (EP) additives, chemically active hypoid oils, substances or agents binding the lubricating film are used, introducing them to the base oil [5].

Aqueous CLLs include aqueous oil emulsions (AOE) and other aqueous solutions. Emulsions are dispersion systems that are formed by mixing two immiscible liquids, with the dispersion phase being water and the dispersed phase being oil. An aqueous oil emulsion is formed after diluting the oil concentrate (enriched with additives) with water. AOE is used as CLL when the cooling properties of the liquid are more important than lubrication, and it is important to reduce process costs. The oil can be evenly mixed in the entire volume of water by so called emulsifiers. The oil content of an emulsion is generally between 2 and 5\% [1, 3], and its physical properties are clearly better than those of water. AOEs have a specific heat capacity of $4.18 \mathrm{~kJ} /(\mathrm{kg} \mathrm{K})$, which is almost twice as high as that of oil. The thermal conductivity of the emulsion is $0.63 \mathrm{~W} /(\mathrm{m} \mathrm{K})$ and its value is also significantly higher than that of oil [1]. Depending on the size of oil drops (proper emulsifier selection), emulsions are distinguished:

- with large particles of dispersed phase (oil drops of $1-10 \mu \mathrm{m})$,

- with fine particles of dispersed phase (oil drops of $0.1-1 \mu \mathrm{m})$,

- colloidal dispersion (oil drops of less than $0.001 \mu \mathrm{m}$ ).

Non-emulsifying aqueous solutions include: aqueous solutions of surfactants, electrolytes and suspensions. The aqueous solutions used in the grinding process consist of over $90 \%$ water. In practice, it has also been accepted to use combined sets, which include aqueous solutions of salts and surfactants simultaneously. Aqueous solutions may or may not contain mineral oil, the lack of which indicates that CLL is more suitable for cooling and washing out grinding products from the processing zone than for lubrication. The use of aqueous solutions as CLL avoids foam formation problems. Aqueous solutions are characterized by less favourable lubricating properties and higher resistance to microorganisms as compared to emulsions [1].

In order to better meet all CLL requirements, appropriate additives are used in their composition. They affect various CLL properties and should be activated by high pressure and temperature occurring in the grinding process [6]. Additives can be divided into the following groups:

- additives that change the physical properties of CLL (e.g. viscosity index enhancers),

- additives changing the chemical properties of CLL (e.g. oxidation inhibitors),

- tribologically active additives, i.e. those that change the friction conditions: polarizing additives, friction modifiers, antiwear additives, EP type lubricating additives. 
The selection of an appropriate CLL is extremely important for the proper course of the grinding process due to significant differences in their biological, physical and chemical properties [7]. With better grain lubrication, the normal component of the grinding force $F_{n}$ increases due to a higher depth of microcutting and at the same time the efficiency of chip removal from the machining zone is limited. As a result, in order to process a certain amount of material in a predetermined time, the momentary number of cutting points must increase. Therefore, for the small material removal rate (MRR) $Q_{w}$ values, the normal force $F_{n}$ takes a higher value when using oil than when using CLL miscible with water. On the other hand, the value of the tangential component of the grinding force $F_{t}$ decreases due to lower friction of the rake and side surfaces of the grains, therefore, despite a higher number of cutting points and good lubrication, a lower value of the tangential component $F_{t}$ of the total grinding force $F_{c}$ is obtained [3]. Increasing the CLL output leads to a decrease in friction, which in turn reduces the value of the tangent component of the force $F_{t}$, and further the total grinding force $F_{c}$. Also the composition of oil or aqueous oil emulsion has a significant effect on the grinding force. It should be noted that the influence of differences in the CLL composition depends largely on the conditions of the grinding process, e.g. the type of workpiece material [3].

The issue of the influence of the CLL type on the formation of undesirable thermal defects, such as burns, structural changes and unfavourable state of stress in the surface layer of the workpiece (tensile stress may result in the formation of micro-cracks and peeling of the surface of the workpiece) is also of great practical importance. However, the influence of the CLL type on the risk of thermal defects in grinding processes cannot be clearly determined as it depends largely on the specific conditions of machining in a given application [3].

In grinding processes with a high MRR $Q_{w}$, the use of oils allows for more favourable results in terms of grinding wheel wear and surface quality than AOE delivery. On the other hand, aqueous CLL should be recommended for use in fine grinding processes as they provide greater dimensional and shape accuracy as well as a lower risk of surface thermal defects due to the lower values of the normal grinding force component $F_{n}$ and their ability to transfer heat from the GWAS-workpiece contact zone faster. Moreover, the use of oil in precision grinding may hinder chip formation in the grinding zone due to small cross-sections of the cut layer per single cutting vertex of active abrasive grain in this type of process [3].

\subsection{Cooling Gases}

In the literature sources can be found also descriptions of grinding processes carried out with the use of a gas coolant.
Most often these are the processes of so-called cryogenic cooling with the use of $\mathrm{LN}_{2}$ [5, 8-11], liquid $\mathrm{CO}_{2}$ [12-17] or descriptions of the possibility of using cooled compressed air (CCA) [18].

Cryogenics is a field that covers the properties and application of materials in extremely cold environments. A gas is assumed to be cryogenic if it can be converted into a liquid by taking heat from it and by lowering its temperature to very low values. The cryogenic limit is not strictly defined, but a temperature value below $-150{ }^{\circ} \mathrm{C}$ is usually taken as the limit. The cryogenic cooling method belongs to alternative methods of cooling the grinding zone, the application of which allows to reduce the CG flow rate taking part in the grinding process [5]. The basic cooling medium in this method is $\mathrm{LN}_{2}$ - a safe and environmentally friendly gas, which in almost $78 \%$ of its volume is part of the atmospheric air [8]. $\mathrm{LN}_{2}$ is obtained through condensation and fractional evaporation of atmospheric air. The melting point of pure nitrogen is $-210{ }^{\circ} \mathrm{C}$ (such a value is maintained by $\mathrm{LN}_{2}$ during post-slow boiling) whereas the boiling point is about $-198^{\circ} \mathrm{C}$ [9]. The use of $\mathrm{LN}_{2}$ enables not only cooling but also lubrication of the grinding zone as together with $\mathrm{LN}_{2}$ a mist is formed which surrounds the liquid stream and acts as a lubricating buffer layer in the grinding zone $[10,11]$.

Liquid carbon dioxide $\left(\mathrm{CO}_{2}\right)$ is a cheaper alternative to $\mathrm{LN}_{2}$. In the literature there are examples of its use mainly in relation to machining processes [12-15]. Cordes et al. [12] described the results of research on the milling process of high strength stainless steel under the conditions of liquid $\mathrm{CO}_{2}$ delivery. Compared to the results of dry milling, a higher machining efficiency and lower tool wear were noted. Jerold and Kumar [14] described the possibility of using liquid $\mathrm{CO}_{2}$ to reduce the temperature and roughness of the treated surface in comparison with the results of the machining carried out under flooding conditions. When machining Ti6Al4V Patil et al. [15] found that liquid $\mathrm{CO}_{2}$ effectively cools the machining zone, allowing to control surface strength and roughness at low speed and depth of cut, while $\mathrm{LN}_{2}$ provided more favourable results with increased cutting performance. However, research works are also in progress on the possibility of using liquid $\mathrm{CO}_{2}$ in grinding processes, as a cooling aid in the use of air-oil aerosol enabling further minimization of CLF output $[16,17]$.

There are processes in industry that exclude the use of CLL because they require the workpiece to be kept dry. In such a situation, the delivery of air stream allows for improved cooling during the grinding process without using CLL. The water vapour in the airstream can have a positive effect on the cooling properties in the grinding zone. Water vapour improves the cooling efficiency and ensures low lubrication, especially when cooling takes place in the air, not nitrogen environment [18]. The basic advantage of cooling the grinding zone with the use of air as the cooling 
medium is connected with the elimination of costs connected with the acquisition and disposal of CLL.

\subsection{Antiadhesives and Lubricants in Solid State}

Lubricants and antiadhesive agents can also be introduced into the machining zone in solid state (especially in dry grinding processes). This is realized by direct delivery to the machining zone solid lubricant, mixing of CLF with powdered solids or in the form of a wheel impregnate. Impregnation of grinding wheels is designed to [5, 19-24]:

- reinforcement of the grinding wheel structure and reduction of the phenomenon of shape (edge) wear, which is particularly important in the process of shape grinding with grinding wheels whose GWAS profile outline is mapped on the surface of the workpiece [20,21,23];

- reduction of strength of the machined surface by chemical separation of the freshly exposed machined surface from the chips and the tool surface through its oxidation and introduction of protective layers;

- chemical etching of the workpiece surface leading to the reduction of cutting resistance increasing the machining efficiency;

- reduction of temperature in the grinding zone by reducing the friction between the abrasive grains and the workpiece material through the formation of lubrication films and endothermic reactions,

- preventing adhesion of chips to the workpiece surface and the GWAS.

Inorganic or mixed substances are most often chosen for impregnation. According to the nature of impact on the abrasive machining process, impregnats can be divided into the following groups $[1,25]$ :

- passive chemical (hydrocarbons, resins, etc.),

- surface active (detergents, soaps, etc.),

- corrosive active (electrolytes),

- chemically active (forming chemical compounds e.g. with sulphur).

Although the idea of impregnating grinding wheels is not new, it still shows great application potential, especially thanks to developments in applied chemistry. In recent years, lubricants and antiadhesive agents such as graphite, Teflon ${ }^{\circledR}$, molybdenum disulfide $\left(\mathrm{MoS}_{2}\right)$, hexagonal boron nitride (hBN), wax, paraffin wax, as well as silicone are introduced into the volume of the grinding wheel by gravity or pressure methods. Solid lubricants and antiadhesive agents are also added to CLF in powdered form, e.g. to air-oil aerosols or emulsion aerosols [26-36].
The rapid development of nanomaterial science has also been reflected in grinding processes, resulting in research on the impact of adding nanoparticles in the form of $\mathrm{Al}_{2} \mathrm{O}_{3}$, $\mathrm{MoS}_{2}$, carbon nano-tubes (CNT), graphene or diamond to CLF. Nanoparticles are added to CLF because of their high thermal conductivity and advanced tribological characteristics. CLF enriched with nanoparticles is characterized by changed heat conduction properties and different, in comparison with conventional cooling of the grinding zone, by heat exchange, reducing the phenomena of grinding energy dissipation and lowering the workpiece surface temperature [37-39].

\section{Conventional Methods of Delivery Coolants, Lubricants and Antiadhesives in the Grinding Processes}

\subsection{Methods of Delivery Cooling and Lubricating Liquids}

Both the flow rate and the way the CLL is delivery into the machining zone have a significant impact on the grinding process. Many different nozzle types have been designed to meet the numerous requirements for how the CLL is applied to the grinding zone (Table 1). In general, there are three criteria for dividing the nozzles [1]:

- by function (flooding, non-flooding),

- due to the concentration method (free jet nozzles, concentrated jet nozzles-spot nozzles, swell nozzles, spray nozzles),

- due to the geometry of the nozzle (squeezed pipe, needle nozzles, shoe nozzles).

The main task of all nozzle types is to deliver the CLL to the grinding zone. The nozzle performs this task by focusing and directing the CLL jet as well as accelerating it. A beneficial effect on cooling performance can be observed by concentrating the liquid stream, which involves minimizing flow disturbances through sharp edges at the nozzle outlet or through an extended parallel nozzle outlet. Moreover, it is necessary to achieve the maximum flow velocity, which is achieved by reducing the cross sectional area at the nozzle outlet to wet GWAS by CLL [1].

The flooding method is a commonly used way of delivering CLL to the grinding zone for various types of grinders. The CLL is pumped and directed to the grinding zone through a slotted nozzle. The cooling lubricant discharge velocities reach the order of $v_{C L L}=1 \mathrm{~m} / \mathrm{s}$. As the contact surface between the workpiece and the grinding wheel increases, the width of the wheel and the density of the wheel structure increases, and as the size of the 
Table 1 Examples of cooling and lubricating liquids delivery methods in surface grinding processes (on the basis of [40-44])

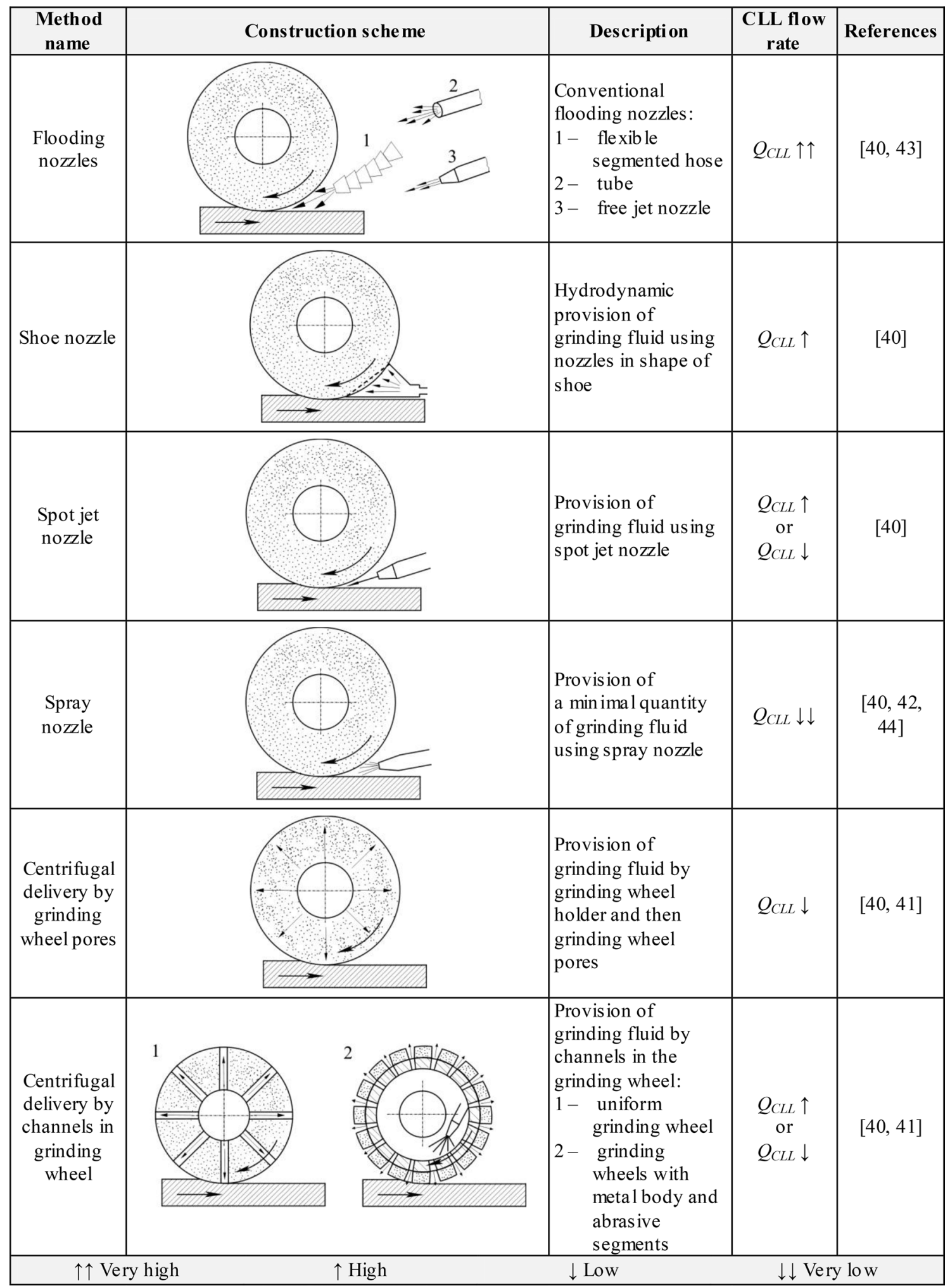

wheel grains decreases, the CLL delivery intensity should increase. Moreover, the higher the requirements concerning surface quality, the more complex the shape of the workpiece and thinner its wall (in case of a hollow object), the intensity of CLL delivery must be higher. In the case of cylindrical grinding and grinding of flat surfaces by the 
grinding wheel's circumference, the fluid flow should not be less than $8-10 \mathrm{~L} / \mathrm{min}$. In case of centerless grinding, the value of CLF output should not be less than 3-6 L/min for each $10 \mathrm{~mm}$ of GWAS contact length with the machined surface, whereas in case of face grinding of flat surfaces, the value should be $10-15 \mathrm{~L} / \mathrm{min}$ for each $10 \mathrm{~mm}$ wide of abrasive ring or segment [1].

The CLL's performance in the form of a free flow that is fed to the grinding zone at low speed is significantly influenced by the rotating air stream that is generated by the grinding wheel. This is the phenomenon of the so-called air cushion, which surrounds the grinding wheel around its circumference, and already at the peripheral speed of the wheel $v_{s}=20 \mathrm{~m} / \mathrm{s}$ it causes deflection and spraying of the liquid stream. The air cushion is the main obstacle for the CLL, which makes its interaction with the GWAS difficult during grinding and limits the CLL's access to the machining zone. Increasing the supply pressure to the CLL is one of the effective ways of preventing this phenomenon. Moreover, other methods of air cushion elimination have been developed, such as the use of shoe nozzles, spot jet (jet-pressure) nozzles, off-zone CLL delivery or centrifugally through the grinding wheel [1].

The jet-pressure method differs from the conventional flooding method by only increasing the pressure CLL to more than 1-1.5 $\mathrm{MPa}$. The increased pressure allows to increase the speed of the liquid delivered, and thus to overcome the resistance of the air stream. As a result, CLL penetrates the grinding zone and the intensity of lubrication and heat dissipation from the ground surface increases significantly. In order to obtain better effects, the minimum distance between the nozzle and the grinding wheel should be selected and the angle of the nozzle setting in relation to the grinding wheel should be determined. The CLL flow should be directed tangentially to the peripheral surface of the grinding wheel, whereas the value of its flow velocity $v_{C L L}$ should oscillate around the value of the peripheral speed of the grinding wheel $v_{s}$. When this condition is not maintained and the difference between $v_{C L L}$ and $v_{s}$ is significant, then the laminar flow of the CLL flow at the point of contact changes into a turbulent flow and the flow itself deviates from the grinding wheel. At low discharge speeds, the CLL jet delaminates due to surface tension and axial waves. Increasing the CLL flow velocity contributes to improving cooling in the grinding zone and reducing the surface roughness of the workpiece. The CLL flow rate must be high enough to fill the grinding wheel pores. However, delivery CLL at too high a speed causes dispersion of the coolant stream, which may result in insufficiently effective filling of the grinding wheel pores by CLL [45-47]. Examples of special needle nozzles for CLL delivery to the grinding zone manufactured by Grindaix $\mathrm{GmbH}$ were shown in Fig. 1. These are nozzles with special geometry with optimized flow dynamics (including those manufactured using additive techniques), individually adjusted to the specific grinding operation.

An interesting solution are the methods of centrifugal delivery of CLL to the grinding zone, used both in the case of relatively large grinding wheels in the process of surface, shape and external cylindrical grinding, as well as in small size grinding wheels intended for internal cylindrical grinding [40, 41, 49-53]. The most important advantages of CLL centrifugal delivery to the contact zone of the grinding wheel with the workpiece may be considered:

- much more effective (than in the flooding method) reaching the CLL to the grinding zone, allowing the reduction or elimination of thermal defects of the machined surface,

- a significant improvement in grinding zone cooling and lubrication compared to the most common flooding method,

- possibility of limiting the CLL flow rate while meeting the technological requirements of the macining, thanks to which it is possible to obtain a favourable economic and ecological effect.

However, these methods also have several disadvantages, the most important of which are:

- the necessity to use special systems of CLL delivery,

- when delivering CLL through the pores of a grinding wheel, the cooling effect depends largely on the openness of the wheel structure,

- in many cases, the need for an unconventional grinding wheel body design.

When using the CLL centrifugal delivery through the tool, the coolant should be thoroughly filtered to avoid clogging of the grinding wheel pores. The concentration of mechanical impurities in CLL must not exceed $0.03 \%$, whereas for fine grinding wheels this value should be even lower. Keeping this condition is important both for maintaining an appropriate CLL flow rate and to avoid structural imbalances which increase the vibrations of the spindle system which occur when the grinding wheel pores get clogged [50].

\subsection{Methods of Delivery Cooling Gases}

As already mentioned in Sect. 2.2, the most commonly used cooling gases are liquid $\mathrm{LN}_{2}$ (cryogenic cooling) and cooled compressed air. This section describes the methods of delivering these gases into the machining zone, as well as their influence on the grinding process and its results.

The use of $\mathrm{LN}_{2}$ as a cooling medium in the cryogenic cooling method is characterized by high availability of the 
Fig. 1 Specialized needle nozzles by Grindaix $\mathrm{GmbH}$ : a for external cylindrical grinding; b for internal cylindrical grinding; $\mathbf{c}$ for surface grinding; $\mathbf{d}$ for surface profile grinding; $\mathbf{e}$ for centerless grinding; $\mathbf{f}$ example of needle nozzle [48] a)

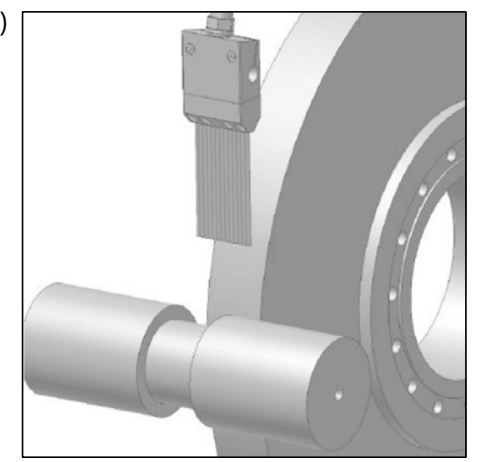

c)

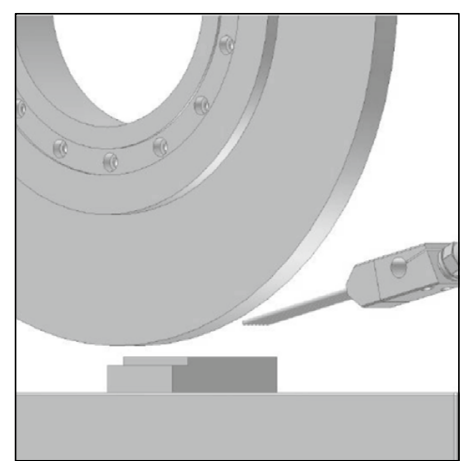

e)

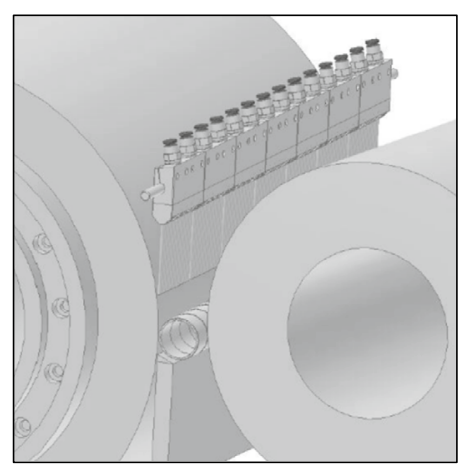

b)

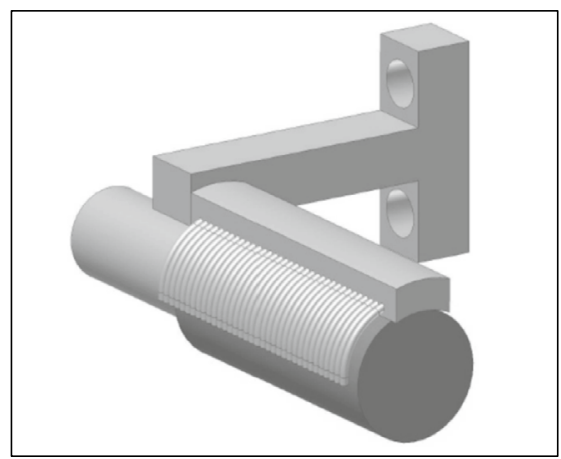

d)

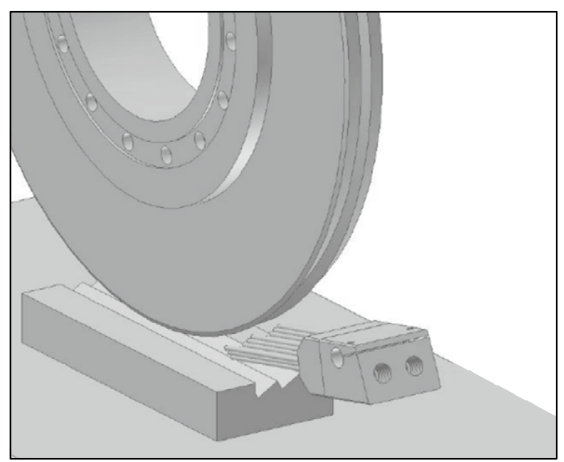

f)

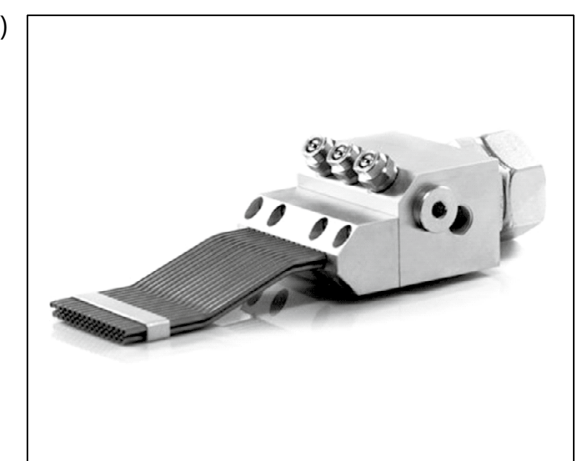

medium, easy handling and relatively small amount of necessary equipment required to obtain $\mathrm{CG}$. Due to nitrogen inertia for the environment and human health, there is no need to apply additional safety measures apart from protection against low temperature $[9,54]$.

Chattopadhyay et al. [55] demonstrated the beneficial effect of $\mathrm{LN}_{2}$ delivery on the reduction of grinding force components and improvement of machined surface quality (reduction of surface defects in the form of microcracks). The results of studies by Paul et al. [56] indicate that the application of cryogenic cooling with $\mathrm{LN}_{2}$ to steel grinding processes significantly reduces the temperature in the grinding zone. Drastic reduction of the temperature value in the grinding zone and maintaining it at a sufficiently low level has a significant impact on the reduction of residual tensile stress values and general improvement of parameters in the process of grinding steel with cryogenic cooling. The phenomenon of oxidation and the formation of burns on the workpiece surface during grinding using the cryogenic cooling method has been completely eliminated, as well as the formation of cracks on the workpiece surface, plastic deformations and pulling of abrasive grains [56, 57]. Moreover, Paul et al. $[56,57]$ point out that the application of the cryogenic method may increase the value of the parameter $R a$ determining the surface roughness of the workpiece, with reference to the grinding with the use of flood cooling and in some cases also with reference to dry grinding [56]. On the other hand, Nguyen et al. [58] demonstrated that when $\mathrm{LN}_{2}$ is delivered to the grinding zone, its high evaporation rate increases even more due to turbulent air flow generated by the grinding wheel rotation. As a result, the delivery of $\mathrm{LN}_{2}$ to the grinding zone is significantly limited and only a small amount of CLF is delivered to the GWAS contact zone with the workpiece surface. Nguyen et al. [58] prove that heat dissipation due to boiling of $\mathrm{LN}_{2}$ is effective only near the grinding zone. For this reason, an increase in temperature occurs in the grinding zone, which results in intensive evaporation of $\mathrm{LN}_{2}$. Moreover, $\mathrm{LN}_{2}$ is a relatively 
expensive $\mathrm{CG}$, for this reason the cryogenic cooling method should be used in grinding processes of machine elements with increased accuracy or quality requirements, which are subjected to high loads and whose defect would be connected with high losses. The $\mathrm{LN}_{2}$ stream should be properly controlled and delivered only at the moment of contact of GWAS with the surface of the workpiece, which would allow minimizing the output of relatively expensive CG [54, 56]. Reddy and Ghosh [59] demonstrated a positive effect of the cryogenic cooling method using $\mathrm{LN}_{2}$ on the extension of grinding wheel life with a simultaneous increase in the value of grinding ratio $G$ (in comparison with the results obtained in the cooling conditions of the grinding zone with the use of emulsion delivered by the flooding method), due to excellent cooling properties of the method. The increase in the value of grinding ratio $G$ is, according to the authors, caused by the increase in the strength of the bond of the grinding wheel in such conditions. Moreover, experimental studies have shown that the use of $\mathrm{LN}_{2}$ as $\mathrm{CG}$ may have an influence on increasing the values of parameters $(R a, R z$, $R t)$ of the workpiece surface roughness and on decreasing the efficiency of the grinding process using grinding wheels with $\mathrm{Al}_{2} \mathrm{O}_{3}$ abrasive grains and ceramic bond. It has also been shown that the application of the cryogenic cooling method increases the power consumed by the grinder spindle in relation to the grinding process with the use of flooded cooling and oil as CLL [59].

The method of cooling the machining zone with a stream of cooled compressed air is based on the use of cold air guns (CAG) and the descriptions of its use in machining processes and grinding can be found in [60, 61]. Supporting the grinding processes with the application of a cooled compressed air stream may significantly reduce the temperature in the grinding zone and allow to reduce or completely eliminate the occurrence of thermal defects $[62,63]$. The equipment used to obtain and deliver cooled compressed air to the grinding zone is characterized by uncomplicated construction, low purchase cost and easy operation. The CAG nozzle is a device which allows to create a stream of cooled compressed air by using vortex tubes in their construction.

Ramesh et al. [64] have shown a decrease in the value of grinding force during the grinding process under the conditions of delivering a stream of cooled compressed air (with a pressure of $0.3 \mathrm{MPa}$, air temperature at the nozzle outlet in the range from -30 to $-35{ }^{\circ} \mathrm{C}$, flow rate of $0.4 \mathrm{~m}^{3} / \mathrm{min}$ ) in comparison with the grinding using the flooded cooling method, with a specific MRR up to $Q^{\prime}{ }_{w}=1.6 \mathrm{~mm}^{3} / \mathrm{mm} \mathrm{s}$ for S45C steel and up to $Q^{\prime}{ }_{w}=1 \mathrm{~mm}^{3} / \mathrm{mm} \mathrm{s}$ for SS304 steel. Choi et al. [65] in their research showed that the application of $4 \% \mathrm{AOE}$ for cooling and lubrication of the grinding process allows to obtain a lower value of roughness parameters $R a$ and $R z$ than in the case of delivering CCA to the grinding zone. In their opinion, this results from the lack of lubrication and very limited possibility of cleaning the surface of the workpiece and GWAS, as compared to the process carried out with AOE. Choi et al. [62] described the results of studies on the effect of CCA delivering on the internal cylindrical grinding with cubic boron nitride and $\mathrm{Al}_{2} \mathrm{O}_{3}$ abrasive grains. It has been shown that with a decrease in the temperature value of the CCA stream and an increase in its discharge velocity, the value of roughness parameters $R a$ and $R z$ of the machined surface decreases and the phenomenon of thermal defects of the machined object is reduced. Moreover, it has been observed that the value of tensile stress occurring in the surface layer of the workpiece after grinding decreases with an increase in the CCA flow rate from the nozzle [62]. Lee and Lee [60] optimized the microgrinding process with the use of CCA. The optimization of the process allowed to limit the specific grinding force $F{ }_{c}$ and to reduce the value of the workpiece roughness parameter $R a$, at the same time maximizing the specific MRR $Q^{\prime}{ }_{w}$, thus indicating the great potential of this method. Cooling the grinding zone with the use of CAG nozzles in a very effective way allows to minimize the occurrence of grinding defects on the machined surface and, moreover, their use allows to reduce the negative impact of CLF on the environment, which is consistent with the current trend of development of manufacturing techniques [65].

\subsection{Methods of Delivery Antiadhesives and Lubricants in Solid State}

Many solid antiadhesives and lubricants (described in more detail in Sect. 2.3) are used in grinding processes: graphite, Teflon ${ }^{\circledR}$, molybdenum disulphide $\left(\mathrm{MoS}_{2}\right), \mathrm{hBN}$, wax, paraffin, as well as silicone. The antiadhesive agents and solid lubricants are most often applied to the grinding wheelworkpiece contact zone with the following methods:

- delivering of powdered solid lubricants as suspensions and pastes together with CLF or in the form of wheel fillers with a resin bond,

- by continuous application to the GWAS before the grinding zone or by using grinding wheels with segments of solid lubricant,

- or by impregnation of abrasive tools with ceramic bond.

The solid lubricants and release agents are delivered into the grinding zone, e.g. by applying graphite or Teflon ${ }^{\circledR}$ in front of the grinding zone, which fills the intergranular spaces of the grinding wheel and thus effectively enters the grinding zone. There are also known solutions consisting in introduction of peripherally arranged segments made of solid lubricant [25, 66-68].

Impregnation of abrasive tools is the process of introducing additional substances actively influencing the grinding 
conditions on the active surface or to the entire volume (intergranular spaces) of the abrasive tool [5, 19-23]. Hartmann wrote about impregnation with sulphur as early as in 1927 [21], but it is still used today. In the machining industry for high-quality steels in the production of rolling bearings and in the metallurgical industry for grinding non-ferrous metals, impregnation with sulphur, copper, paraffin, wax, molybdenum disulphide, colophony and other substances is used [5, 69-71]. Companies producing abrasive tools (Super Abrasives, Global Systec Shur Grind Segments, Grier Abrasive, Inc., Joto Abrasives PVT.LTD, Norton Company) offer impregnated wheels. Their offer includes wheels impregnated with sulphur, resin or wax. One of the most frequently used methods of impregnation of abrasive tools is direct immersion of molten impregnant in the pores of the wheel. Gravity as well as pressure methods are known in this area. After the impregnant has cooled down, the wheel is ready to work [19-23].

\section{Environmentally Friendly Hybrid Methods of Delivery Coolants, Lubricants and Antiadhesives in the Grinding Processes}

In addition to the benefits of coolants, however, a number of economic and ecological problems arise. These include, on the one hand, the costs of purchase, use and maintenance, and, on the other hand, the environmental impact of the disposal of the liquids. Coolant components such as bacteriocides and fungicides, reaction products formed in CLL and containing foreign substances can become a major cause of skin and respiratory diseases for operators. Leaks of harmful substances, as well as water used to clean cooling systems, are sources of contamination of soil, water and air. CLL is disposed of either chemically (by refining and thermal cracking) or by biodegradation. They can also be burned and recovered by cleaning. These processes are expensive and often significantly burden the environment with their products [72]. These negative aspects of the use of CLL have contributed to the current trend of minimizing their output in machining processes, including grinding. Such a trend has forced the intensification of research aimed at reducing the amount of CLL taking part in the manufacturing processes, and thus getting into the environment. This part of the paper describes the environmentally friendly hybrid methods of delivery coolants, lubricants and antiadhesives in the grinding processes known from the literature.

\subsection{Minimum Quantity Lubrication (MQL)}

The minimum quantity lubrication (MQL) method has been developed to ensure the most favourable conditions for the implementation of the cutting machining processes while minimising the CLF output. In the MQL systems, oil is sprayed under the influence of compressed air energy onto the GWAS and the workpiece surface. Most often the airoil aerosol is delivered to the grinding zone via an external nozzle or nozzle system. In the literature sources [73-75], can often be found a description of a lubrication method with minimum CLF output as a very important alternative to dry grinding. Even a small amount of CLF entering the contact zone between the GWAS and the workpiece can have a positive effect on the grinding process efficiency [76-82]. The MQL method uses a CLF flow rate of 7.2-97.2 $\mathrm{ml} / \mathrm{h}$ (nearly 1000 times less than in the flooding method) and CLF is delivered precisely to the GWAS contact zone with the workpiece surface. The air-oil aerosol covers the GWAS and the workpiece surface, cooling down and applying a lubricating film of oil on the workpiece surface. This allows to reduce the friction force between the abrasive grains and the workpiece surface as well as to reduce the grinding force $F_{c}$ and the amount of heat generated [75-92].

The application of the MQL method gives the possibility to choose from a larger number of CLF types, including less harmful (in relation to conventional methods), biodegradable CLF, which may be based on vegetable oils, synthetic esters, fatty alcohols and others [39, 93].

In the MQL method, the lubrication function is provided by oil, whereas the cooling function is provided mainly by compressed air. This very small amount of CLF delivered to the grinding zone allows to significantly reduce the friction in the GWAS contact zone with the machined surface and limits the adhesion of grinding products to the grinding wheel $[50,94]$. The amount of heat received by air is very limited and its ability to conduct heat is insufficient to efficiently cool the grinding zone [95-98]. The research described by Silva et al. [73] shows that the MQL method provides lubrication at a higher level than the flooded method, however, the cooling function of the GWAS contact zone with the workpiece surface is much less effective. As a result, there is a high risk of the occurrence of grinding burns on the machined surface, similarly as in the case of dry grinding $[99,100]$.

\subsection{Minimum Quantity Cooling (MQC)}

If adequate cooling is required, water-based oil emulsions are used as CLF instead of oil in the MQL method. These are used when cooling cannot be carried out with oil. For this method Weinert et al. [44] use the term minimum quantity cooling (MQC). The lubricating properties of emulsions are clearly inferior to those of oil, but nevertheless they are more advantageous than when using water and air as CLF. The CLF output in processes using the MQC method is usually from 10 to $50 \mathrm{ml} / \mathrm{h}$ [44]. Priarone 
et al. [101] in their tests of cooling efficiency of the machining zone during the turning process of difficult-tocut steels used the MQC method at the CLF flow rate from 6.5 to $115 \mathrm{ml} / \mathrm{h}$. The conducted tests showed that cooling of the machining zone with MQC method with the use of emulsion allows to increase the tool life with respect to the use of water spray as CLF. In addition, it has been shown that increasing the aerosol flow rate further reduces tool wear. So far, the MQC method has not been widely used in industry, therefore the elementary phenomena accompanying it are not yet as well known as in other methods of CLF minimization [101].

\subsection{Minimum Quantity Cooling Lubrication (MQCL)}

The method of minimum CLF flow rate of reduced temperature defined as minimum quantity cooling lubrication (MQCL) consists in delivering special oil (less often emulsion) in low temperature environment to the grinding zone [102-105]. CLF used in this method must be characterized by low viscosity index and low density at negative temperatures. The value of temperature of air, whose task is to transport CLF drops is $-30^{\circ} \mathrm{C}$, which also influences the CLF temperature reduction. The MQCL method enables both lubrication in the cutting zone and cooling of the workpiece and grinding wheel. However, it requires the use of special air cooling units supplying the nozzle [102].

A very small amount of CLF (approx. $8 \mathrm{ml} / \mathrm{h} \mathrm{[102])} \mathrm{is}$ delivered to the grinding zone and this can be done with or without an auxiliary transport medium (e.g. compressed air). The airless system method is based on the fact that the pump delivers the CLF to the tool through supply line in short intervals of precisely measured drops. The method involving the use of an auxiliary medium is characterized by the fact that the CLF is atomized to the nozzle in order to produce very small drops, which are then delivered to the grinding zone in the form of an aerosol [106, 107]. When using oil as CLF, its good lubricating properties are used, which allow for the reduction of friction and adhesion phenomena between the workpiece, GWAS and chips of the machined material. As a result, the amount of heat generated by friction is reduced and the workpiece as well as grinding wheel are kept at a lower temperature than in dry grinding [108].

The effect of direct cooling of the grinding zone with airoil aerosol is relatively small due to the low heat capacity of oil $(1.92 \mathrm{~kJ} / \mathrm{kg} \mathrm{K})$ and air $(1.04 \mathrm{~kJ} / \mathrm{kg} \mathrm{K})$ as well as the small amount of medium involved in the process. Due to their low cooling properties, air-oil aerosols are mainly used as a medium in the MQL method. Emulsions and water as CLF are used much less frequently in the MQCL technique and are mostly used when it is important to cool the tool or workpiece more efficiently than oil can provide [102-108].

\subsection{Cooled Air Minimum Quantity Lubrication (CAMQL)}

Despite the very good lubricating properties of the grinding process, the MQL method is not able to provide as effective cooling of the workpiece and grinding wheel as flooded cooling. This fact is a major constraint on the widespread use of the MQL method in the grinding process [109]. Saberi et al. [110] have evaluated the possibility of grinding the surface of $\mathrm{C} 45$ steel using the cooled air minimum quantity lubrication (CAMQL) method, which consists in bringing to the grinding zone the air-oil aerosol formed in the MQL nozzle fed with cooled compressed air generated by the cold air gun.

The temperature value of the CCA stream delivered to the grinding zone was variable and ranged from $-4{ }^{\circ} \mathrm{C}$ (for CCA stream pressure of $0.1 \mathrm{MPa}$ ) to $14{ }^{\circ} \mathrm{C}$ (for CCA stream pressure of $0.4 \mathrm{MPa}$ ). Application of the CAMQL method allowed to reduce the temperature value by up to $19 \%$, compared to cooling the grinding zone exclusively with a CAG nozzle. Although no significant differences in the coefficient of friction values were observed for different conditions of CLF delivery to the CAMQL grinding zone, there was a slight decrease in the value of grinding ratio $G$, with a lower value of CCA pressure delivered to the grinding zone. A higher CCA pressure value leads to a decrease in the lubrication efficiency of the GWAS contact zone with the workpiece surface, due to the delivery of smaller diameter oil drops to the grinding zone and due to more effective generation of air-oil aerosol in the surrounding air [91].

Saberi et al. [110] point out that the use of cooled compressed air for the MQL method, and thus improving the cooling efficiency of the grinding zone, may significantly reduce the restrictions on the use of MQL method in grinding. The CAMQL method can be successfully used in soft steel grinding processes, while its wider development requires further research [110].

\subsection{Cold Air and Oil Mist (CAOM)}

In the research described by Choi et al. [62] as well as Nguyen and Zhang [63], a system consisting of a CAG nozzle and a MQL nozzle, defined by the authors as cold air and oil mist (CAOM), was used. On the basis of the results of the research it has been shown that the application of the hybrid method of cooling and lubrication of the grinding zone CAOM allows to prevent the formation of changes in the structure of the surface layer of the workpiece material in the form of burns. In addition, there has been a decrease in the value of the grinding force in relation to the dry method. However, due to the accumulation of heat energy in the workpiece, the removal of workpiece 
material with an increased depth (above $a_{e}=15 \mu \mathrm{m}$ ) resulted in grinding burns $[62,63]$.

The studies presented by Nguyen and Zhang [63] show that even a small addition of aerosol in the form of vegetable oils to the stream of cooled compressed air allows to perform the grinding process with increased depth. In such a process there are no burns and the quality of the machined surface is similar to that obtained in the grinding process with CLL. The surface cleaning capacity of workpieces and GWAS, despite the addition of a small amount of air-oil aerosol, is still significantly reduced compared to CLL processes, due to the slightly higher value of the surface roughness achieved. In addition, a clear directivity of the stress profiles was noted (compressive stress in the direction consistent with the direction of wheel feed and tensile stress in the perpendicular direction to the direction of grinding) in surface machined with CAG nozzles with vegetable oils. The reason for this phenomenon may be the unevenness of the heat flow generated by the stream of cooled compressed air [62,63].

At the same time, Yui and Terashima [111] indicate a positive effect of a small amount (flow rate up to $8.6 \mathrm{~cm}^{3} / \mathrm{h}$ ) of vegetable oil addition on the conditions of grinding process with the help of cooled compressed air. The use of vegetable oils allowed to achieve up to $10 \%$ less grinding force and comparable value of surface roughness, compared to the results obtained with conventional oil cooling. The value of grinding ratio $G$ using the cooling method with the use of CAG nozzle and with the addition of vegetable oils increased almost twofold in comparison with the process carried out with the flooded oil cooling [111].

Stachurski et al. [112] applied the hybrid CAOM method during the sharpening process of hob cutters (Fig. 2). The lubricant in the form of an air-oil aerosol was delivered with a flow of $50 \mathrm{ml} / \mathrm{h}$ on the active surface of the rotating grinding wheel, so it was delivered directly to the grinding zone.
Fig. 2 Diagram of the hob cutter sharpening process: a machining allowance; b work cycle; $\mathbf{c}$ hob cutter used in the experimental investigations; d arrangement of the oil mist nozzle (MQL) and the supply nozzle of cooled compressed air relative to the grinding wheel active surface in the CAOM method; e surface roughness parameter $R z$ of rake face HS 6-5-2 hob sharpened with different methods of CLF delivery; f microhardness distribution of HS 6-5-2 hob sharpened with flooding (WET), CCA, MQL and MQL-CCA method (on the basis of [113]). $a-$ total machining allowance, $a_{e}$-machining allowance, $n_{s}$ grinding wheel rotational speed, $R z$-maximum height of the roughness profile, $v_{w}$-workpiece peripheral speed
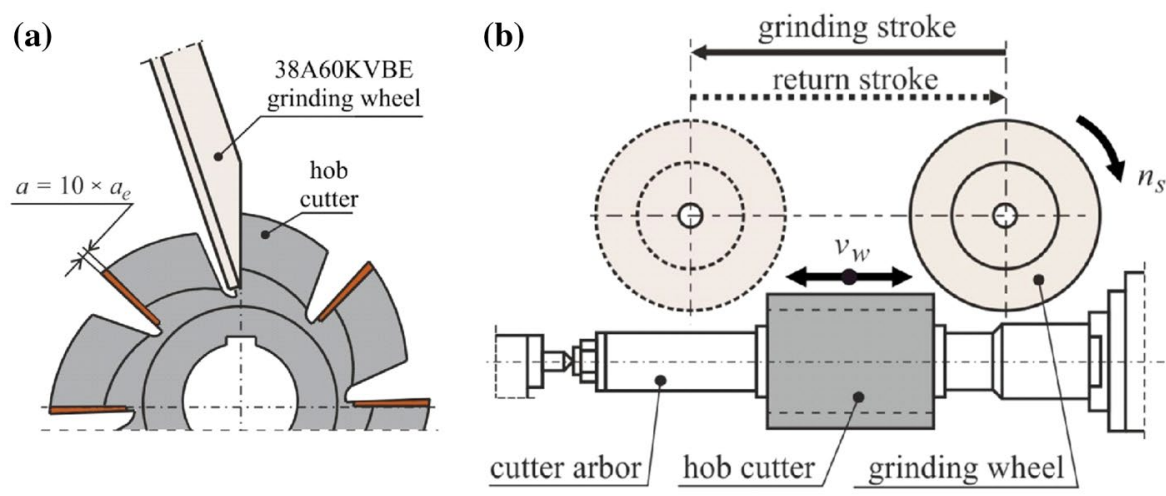

(c)

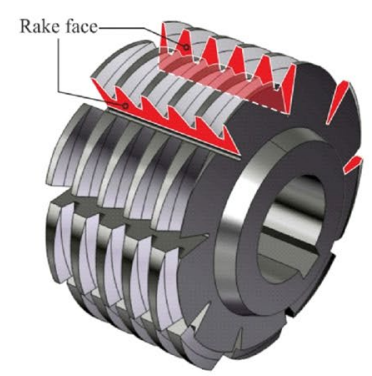

(e)

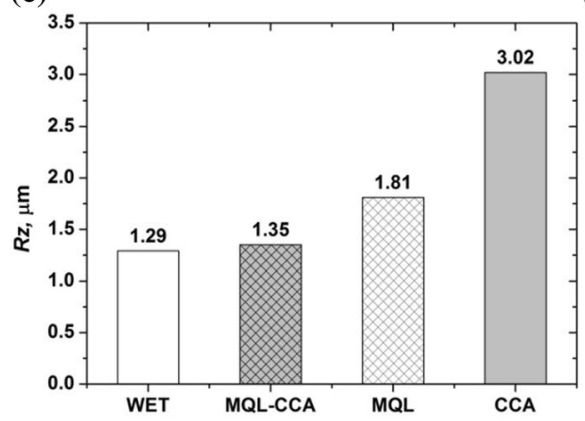

(f)

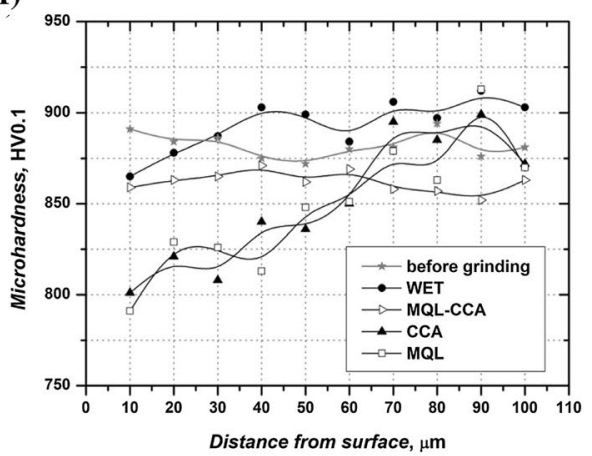


Cooled to $-5{ }^{\circ} \mathrm{C}$, the compressed air has been used mainly as a cooling medium and to minimize the wheel clogging by chips and grinding products remaining after leaving the grinding zone.

The obtained results showed that the application of CAOM method allows to prevent the occurrence of undesirable changes in the structure of the surface layer of the workpiece material in the form of thermal defects. Sharpening of the hob cutters using the CAOM method in terms of the grinding parameters used did not cause any significant changes in the microhardness of the surface layer compared to the flooding method. The results obtained for the MQL and CAG methods used separately indicate a significant, unacceptable decrease in the microhardness of the tool's rake face after grinding $[112,113]$. The roughness of the rake face obtained during sharpening with the CAOM method was similar to the values obtained for the flooding method. Moreover, the cutting edges after CAOM sharpening did not have typical defects in the form of burrs or chipping. SEM images, on the other hand, revealed the occurrence of burrs on the edges of the blades, which were sharpened with MQL method or with CCA [112].

The results of research contained in the works $[62,63$, 111-113] indicate a very high potential for the use of cooling with CAG nozzles, in combination with methods of cooling the grinding zone with a minimum CLF output, which is a noteworthy research direction.

\subsection{Delivery of Solid Powdered Lubricants and Adhesives to the Grinding Zone}

Powdered solid lubricant can be introduced to the GWAS as a suspension or in paste form together with CLF through special nozzles $[2,50,67,68,114,115]$. Although this method achieves a significant reduction in the grinding force, the main limitation is the ineffective removal of the paste together with chips from the GWAS, which can lead to the formation of cloggings.

In recent years, a new trend in the use of antiadhesive agents or lubricating powders in the form of suspensions with emulsifiers and then the use of the prepared dispersion as CLF in the MQL method is becoming apparent in the directional literature. Both oils (MQL method) or water emulsions and distilled water (MQC method) [26-32, 116, 117] can be used as a dispersing phase, as shown in Fig. 3 [118].

Powdered solid lubricants may also be introduced into the abrasive tool in the form of fillers, which are an integral part of the abrasive tool and which do not constitute an abrasive grain or bond. This solution is most often used in the production of grinding wheels with resin bond [119-122].

The rapid development of nanomaterial science has also been reflected in grinding processes, resulting in research

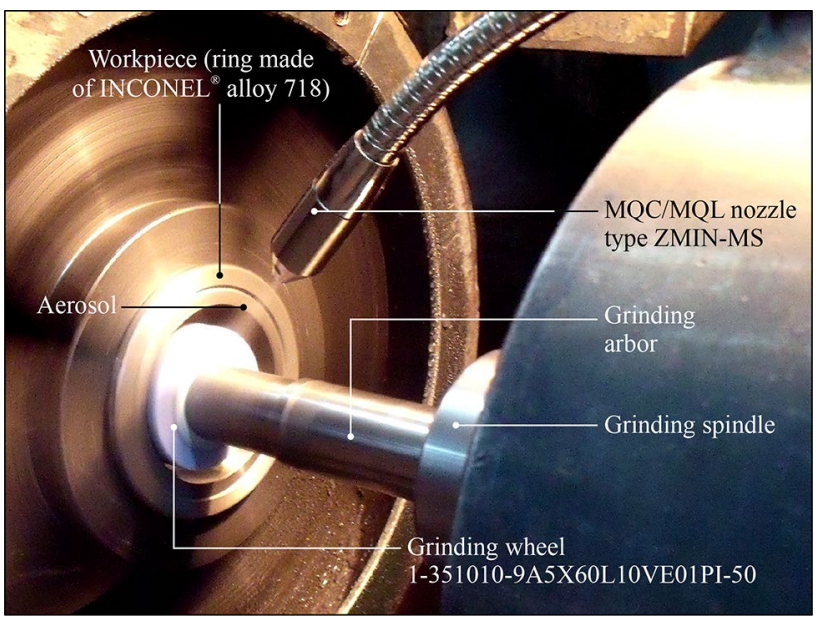

Fig. 3 View of the system for the delivery to the grinding zone of a water aerosol doped with powdered lubricants and antiadhesive agents (on the basis of [118])

to determine the impact of adding nanoparticles in the form of $\mathrm{Al}_{2} \mathrm{O}_{3}, \mathrm{MoS}_{2}, \mathrm{CNT}$, graphene or diamond to CLF. Studies known from the literature describe mainly grinding processes in which nanoparticles are added to CLF delivered to the grinding zone using MQL method [26, 29-32, 37, 38]. Nanoparticles are often spherical in shape and their main role is to lubricate the grinding zone. Due to their spherical form, their presence in the contact zone between the workpiece surface and active cutting grains is compared with the effect of ball bearings [122].

The theory of heat exchange indicates that solids are more capable of heat exchange than liquids, whose heat transfer, in turn, is more effective than that of gases [39, 102]. Based on this theory, solid nanoparticles have been added to the biodegradable oil, resulting in modified CLF, which, similarly to the standard CLF in MQL technique, is delivered to the grinding zone in atomized form [39]. The high-pressure gas is responsible for delivering to grinding zone the CLF rich in nanoparticles, which increases the possibility of heat dissipation from the GWAS-workpiece contact zone and improves the quality of the machined surface. Such modified CLFs are characterized by properties allowing to reduce friction and wear of the wheel $[39,102]$.

Lee et al. [123] compared the efficiency of cooling and lubrication of the grinding zone using compressed air, standard MQL method and MQL method in which CLF was doped with diamond nanoparticles. The highest temperature value, for each of the tested methods, was recorded for the tenth, last pass of the wheel, because of the heat accumulated in the sample after the previous passages, as well as progressive wear of the wheel. The least intense increase in temperature value was recorded when using the MQL method, in which diamond nanoparticles were added to 
CLF. During the last passages of the grinding wheel and at the same time in the most demanding stage of the process, the fastest temperature increase was recorded when using compressed air cooling. A significant reduction in temperature during the grinding process using the MQL method, in which CLF with diamond nanoparticles was used, may be caused by a reduction in the tangent component of the grinding force $F_{t}$. It is connected with intensification of direct lubrication in the machining zone due to tribofilm formed by diamond nanoparticles [124].

Hadadad and Sharbati [99] as well as Li et al. [100] demonstrated that the application of MQL method with CLF doped with nanoparticles (size $50 \mathrm{~nm}$ ) of molybdenum disulfide $\left(\mathrm{MoS}_{2}\right)$ improves the heat dissipation from the grinding zone as well as the lubricating properties of CLF. As a result it is possible to reduce or eliminate thermal defects on the workpiece surface.

Tribological phenomena resulting from the doping of CLF with $\mathrm{MoS}_{2}$ nanoparticles have also been analysed by Kalita et al. [26]. The experimental results they described showed that the addition of $\mathrm{MoS}_{2}$ nanoparticles to the MQL air-oil aerosol in EN24 steel and cast iron grinding process increases the efficiency of the machining by reducing energy losses due to friction. In the most advantageous case (the highest concentration of $\mathrm{MoS}_{2}$ nanoparticles), as much as $53 \%$ reduction in energy demand was recorded, as well as an increase in the value of grinding ratio $G$ by $50 \%$, resulting from the extension of the wheel life.

\subsection{Centrifugal MQL and Delivery of Compressed Cold Air}

One of the ways of supporting the cooling function during grinding using the MQL method is an additional delivering of cooled compressed air known as the CAOM method and described earlier in Sect. 4.5. The described advantages of this method refer to the processes of surface, cylindrical (outer) and shape grinding processes. They were the motivation to undertake work aimed at applying the CAOM method also in the process of internal cylindrical grinding characterized by limited space in the contact zone of the grinding wheel with the workpiece. This is how the method was developed in which a patented centrifugal air-oil aerosol delivering through the grinding wheel [124] was combined while simultaneous incorporating the CAG nozzle into the system [125-127].

The developed method takes into account the need to support the cooling function (implemented in a very limited way by MQL method) as well as the problem of collecting chips on the ground workpiece. The minimum oil flow, delivered in the form of an aerosol in the MQL method, causes that chips and other grinding products are not flushed out of the machining zone, which can cause them to re-enter the
GWAS-workpiece contact zone, disturbing the machining process. The accumulation of chips in the immediate surroundings of the grinding zone also increases the risk of cloggings on the GWAS. Therefore, in the method described above, a two-outlet CCA supply line was used from the CAG nozzle to the machining zone. One end of the supply line was directed in front of the grinding zone to cool it down while the other end was placed directly behind the grinding wheel-workpiece contact zone to support the blowing out of machining products (Fig. 4) [126, 127].

The results of numerical simulations [126] and experimental research [127] have shown that the developed hybrid method allows for about 2.7 times longer wheel life in comparison with the results obtained under flooded cooling or centrifugal MQL conditions. The wheel life was as much as 8 times longer in comparison with the wheel life under SSP only delivering or dry grinding conditions. Precise centrifugal delivery of the lubricant (air-oil aerosol) through the pores of the grinding wheel to the grinding zone and the coolant (CCA stream) directed before and directly behind the grinding zone has made it possible to obtain a grinding ratio $G=150.2 \mathrm{~mm}^{3} / \mathrm{mm}^{3}$. The application of the described method allowed to reduce the friction of dulled grinding wheel vertices resulting from the effective penetration of oil into the zone of their contact with the machined surface, while ensuring stable thermal conditions in the machining zone. As a result, the abrasive wear of the active abrasive grains vertices was reduced and the GWAS retained their cutting ability over a longer time. It has also been shown that the additional CCA stream directed behind the grinding wheel prevents the accumulation of chips in the grinding zone and their re-entry between the GWAS and the machined surface [127].

\subsection{Dry grinding with Impregnated Grinding Wheels and Delivery of Compressed Cold Air}

From an environmental point of view, the grinding process would be best carried out without the use of liquid cooling, lubricating and antiadhesive agents. At the same time, it would make it possible to reduce the costs of grinding operations associated with the purchase, regeneration and disposal of these environmentally hazardous liquids. Dry grinding is possible, however, it is associated with a high risk of thermal defects on the machined surface and a limited life of the grinding wheel, even with a reduced MRR [129, 130]. This is due to the lack of CLL and the elimination of its beneficial effect on tribological conditions of the grinding process. However, some of the CLL functions performed during the grinding process can be replaced by solid or gaseous lubricants and antiadhesive agents. This idea led to the development of a hybrid method of cooling and lubrication 

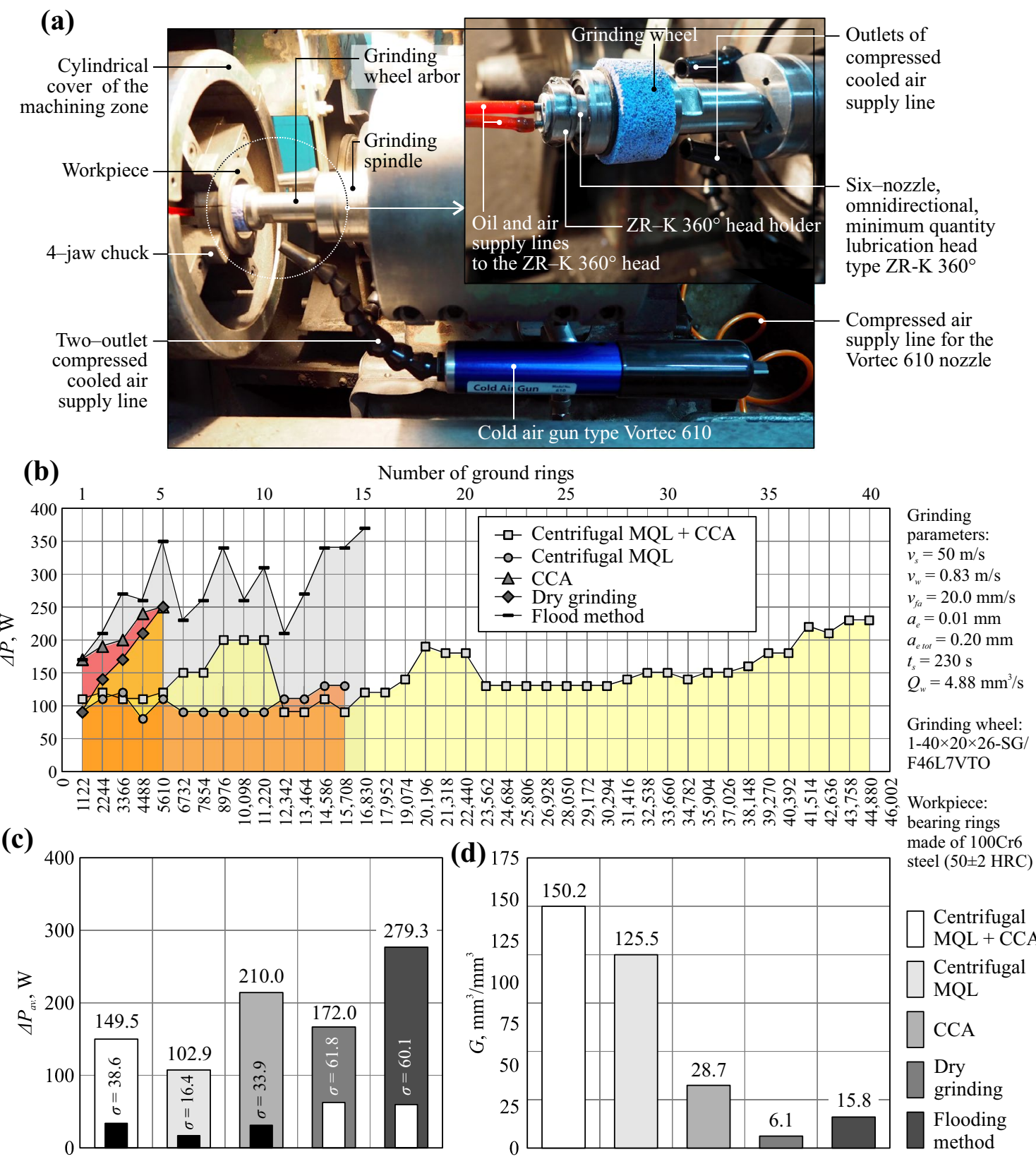

Fig. 4 Internal cylindrical grinding process using a hybrid method of cooling and lubrication integrating centrifugal MQL and cooling with a stream of CCA: a view of the machining zone; $\mathbf{b}$ grinding power

of the grinding zone integrating impregnation of the grinding wheel and cooling with a stream of cooled compressed air.

In the tests of the internal cylindrical grinding process described by Nadolny and Kieraś [131], a small size grinding wheel impregnated with colloidal suspension made with $20 \%$ addition of hexagonal boron nitride $\mathrm{hBN}$ powder was used. Additionally, CCA was delivered generated by the CAG nozzle delivered by compressed air at a pressure of $0.6 \mathrm{MPa}$, which allowed to reduce the gas temperature to gain $\Delta P$ values during grinding wheel lifespan; $\mathbf{c}$ average grinding power gain $\Delta P_{a v}$ with its standard deviation $\sigma$; $\mathbf{d}$ grinding ratio $G=V_{w} / V_{s}$ (on the basis of [127])

about $-5{ }^{\circ} \mathrm{C}$. The CCA task was to cool the surface of the GWAS and the workpiece by absorbing and dissipating the heat generated in the grinding zone, as well as blowing the chips formed during machining out of the grinding wheel's contact zone with the workpiece (Fig. 5).

Experimental research has shown the possibility of five times longer wheel life in the dry grinding process by using the described hybrid method of cooling and lubrication of the machining zone in relation to grinding with a non-impregnated wheel without the delivery of cooling 
(a)

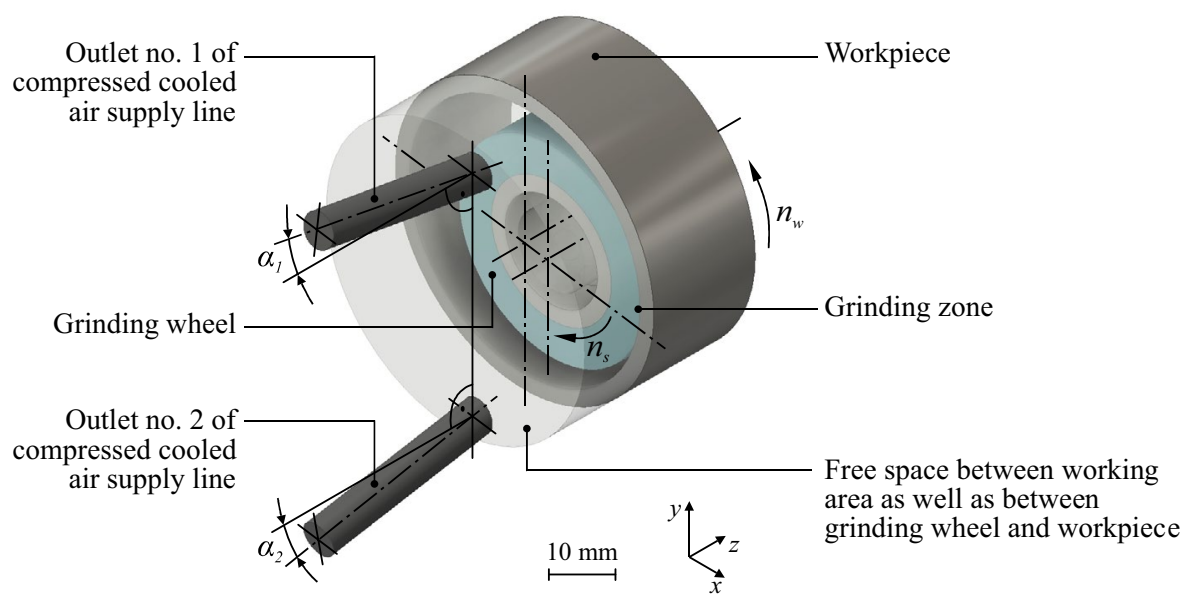

(b)

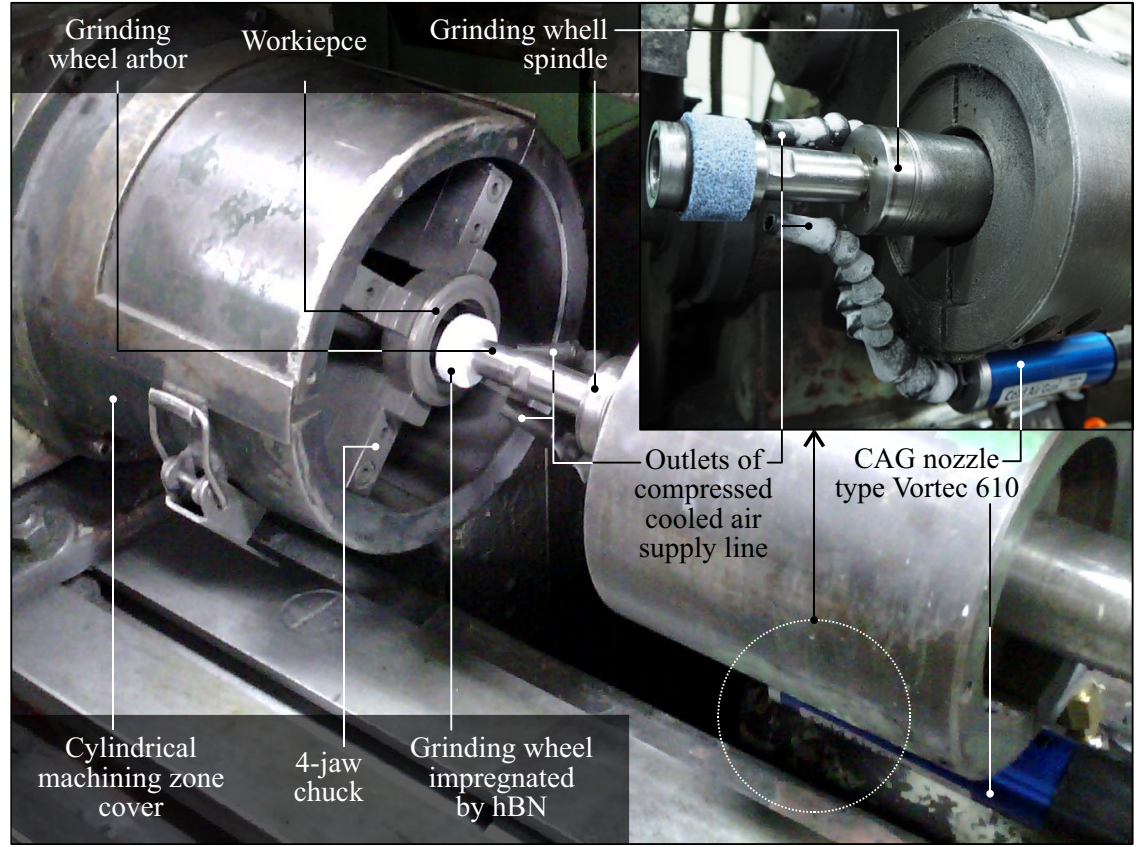

(c)

Number of ground rings

(d)
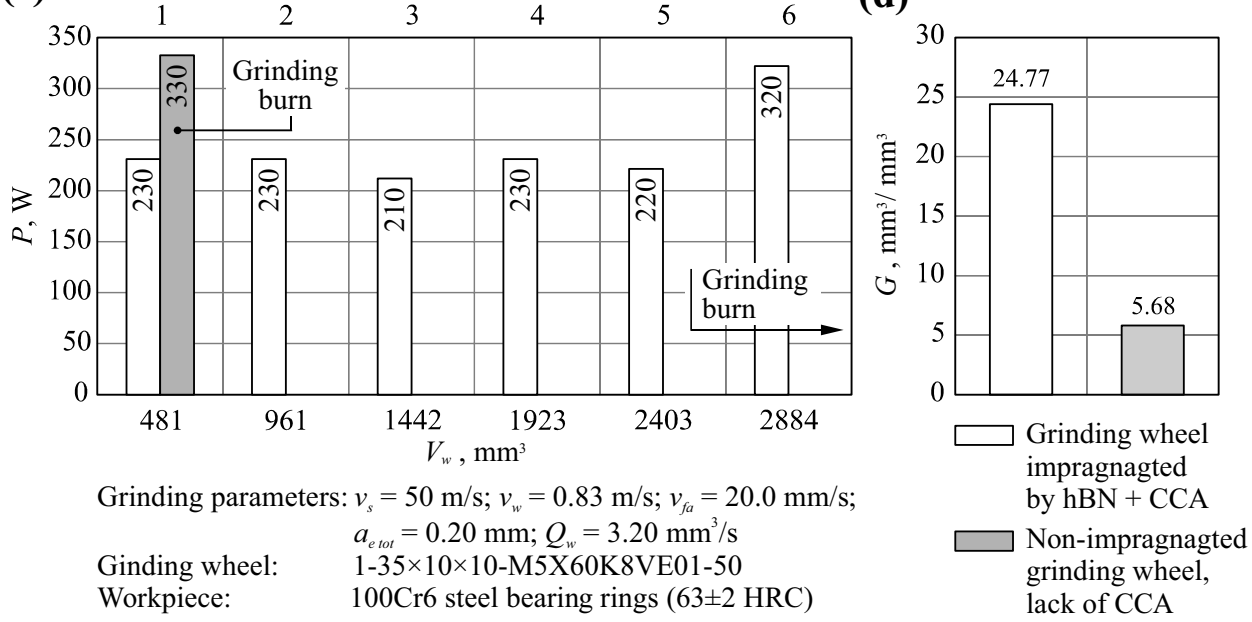
४Fig. 5 Internal cylindrical grinding process using a hybrid method of cooling and lubrication integrating impregnation of the grinding wheel and cooling with a stream of CCA: a layout of the method with the most important kinematic and geometric parameters; $\mathbf{b}$ view of the machining zone; $\mathbf{c}$ grinding power $P$; $\mathbf{d}$ grinding ratio $G=V_{w} / V_{s}$ (on the basis of [131]) $\alpha_{l}$-alignment angle of compressed cooled air supply line outlet no. 1, $\alpha_{2}$-alignment angle of compressed cooled air supply line outlet no. 2

and lubricating agents. In both cases, grinding burns were detected on the machined surface, but under the conditions of using the hybrid method they appeared on the surface of ring no. 6 , and in case of grinding without the delivery of cooling lubricants, already on ring no. 1 . The research has also shown a significant reduction in the volumetric grinding wheel wear $V_{s}$ allowing to carry out the machining in stable conditions with more than 4 times higher value of grinding ratio $G$ than in dry grinding. The beneficial effect of impregnation of the grinding wheel was confirmed by measurements of the surface texture of the GWAS. On the surface of an unimpregnated wheel, the share of flattened areas, which correspond to areas covered with grinding products (cloggings) and smoothed abrasive vertices, was more than three times higher (24.3\%) than that of hBN-impregnated grinding wheel (7.39\%). Microscopic analyses of the $\mathrm{hBN}$ impregnated grinding wheel revealed a relatively small proportion of micro-cloggings on the abrasive grains active vertices, a lot of free intergranular spaces as well as few dulled cutting vertexes. These observations can be explained by the active influence of the impregnating substance on the tribological conditions in the grinding zone resulting in limiting the chip adhesion to the GWAS. On the surface of an untreated wheel, a much higher share and larger sizes of chip cloggings (both single abrasive vertices and intergranular spaces) formed under non-hBN grinding conditions were shown [131].

\section{Summary}

Tables 2, 3 and 4 presents a synthetic overview of the cooling and lubrication agents described in the literature as well as the methods of their delivery to the GWAS-workpiece contact zone in respect of liquids (Table 2), gases and solids (Table 3) as well as hybrid methods (Table 4).

Particularly advantageous seem to be methods combining many media, whose correct configuration and precise implementation in industrial conditions creates an opportunity to carry out the grinding processes without the participation of CLF (which until now has been associated with dry grinding), and yet with effective lubrication (solid-state antiadhesives and lubricants) as well as cooling of the machining zone (CCA stream).
The common feature of the described hybrid methods is a radical reduction of CLF output (or even their complete elimination) allowing to reduce the amount of environmentally harmful substances constituting a by-product of grinding processes, as well as to reduce the costs associated with carrying out such machining. Importantly, this does not adversely affect the quality of the surface to be machined often while extending the life of the grinding wheel. The most important factor determining the effectiveness of modern hybrid methods is the precise delivery of cooling, lubricating and antiadhesive agents in liquid, gaseous or solid state to the contact zone of active abrasive grains with the workpiece surface. Hybrid methods are characterized by the integration of several media in one system, the effectiveness of which depends on the complementarity of functions of individual component factors. In view of the above, it appears that further development work should be carried out on hybrid methods, of which CAOM and delivery of solid powdered lubricants and antiadhesives to the grinding zone should be considered as the most promising.

The most essential directions of further development in the field of cooling and lubrication of the grinding zone can be counted among the most important:

- searching for new types of CLF (e.g. as a result of the spread of nanomaterials) which, with a minimum flow rate, will ensure even more favourable grinding results compared to the substances used so far,

- integration of known techniques for the delivery of cooling and lubrication agents to the grinding zone to eliminate the disadvantages of existing solutions in new hybrid methods,

- the development of knowledge on heat exchange in complex turbulence flow systems and with many cooling and lubrication agents will be possible thanks to increasingly excellent computer modelling and numerical simulation systems,

- searching for new solid substances used for impregnation of grinding wheels, which will effectively perform the lubricating and antiadhesive function and at the same time will not be harmful to the environment (e.g. biodegradable or recycled substances),

- searching for new ways of introducing solid lubricants and antiadhesive agents into the grinding wheel, e.g. as components of a bond or in the form of abrasive aggregates,

- implementation of well-known methods for new types of abrasive tools, e.g. for machining that integrates raw and fine grinding in one operation.

However, it seems that significant qualitative changes in the cooling and lubrication of the machining zone in grinding processes will only be possible through the 


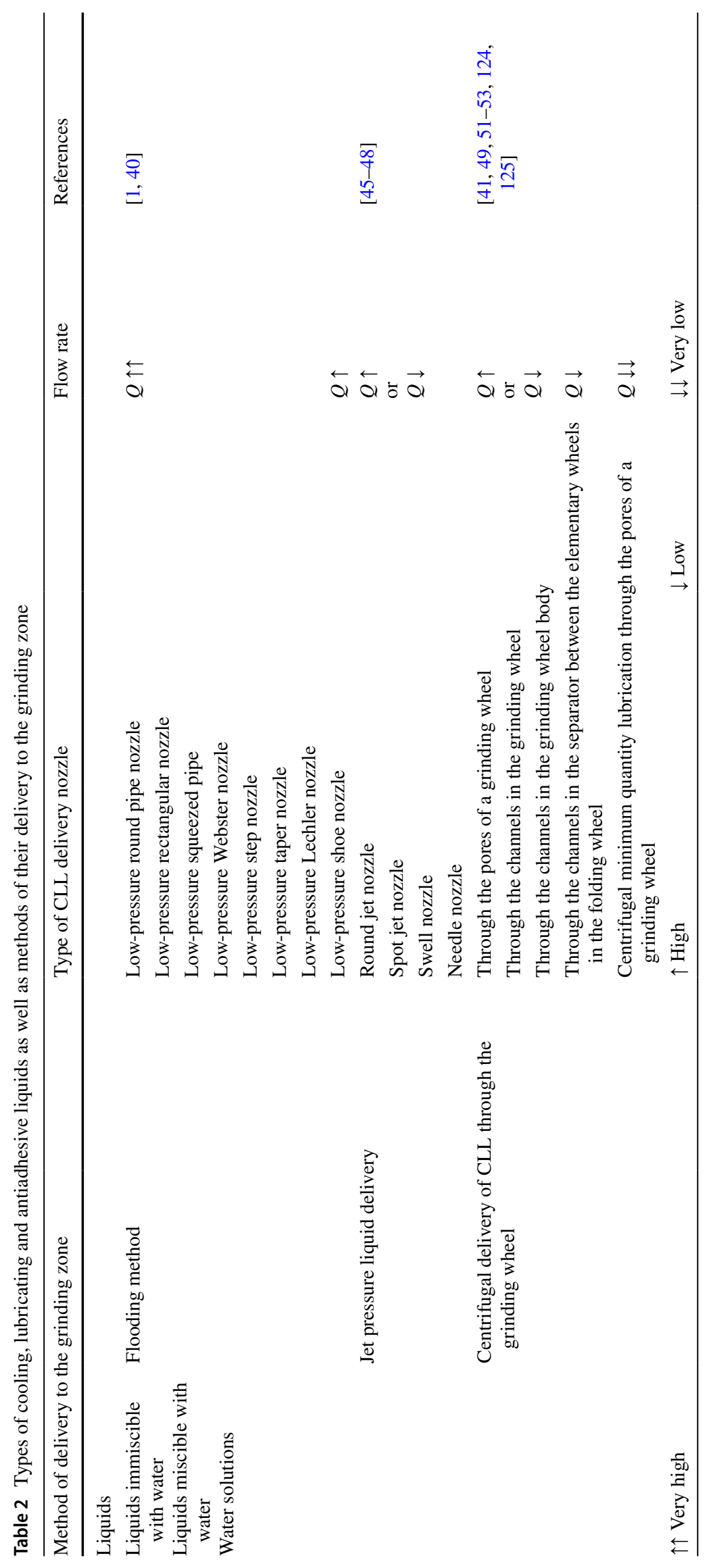


Table 3 Types of cooling, lubricating and antiadhesive gases and solids as well as methods of their delivery to the grinding zone

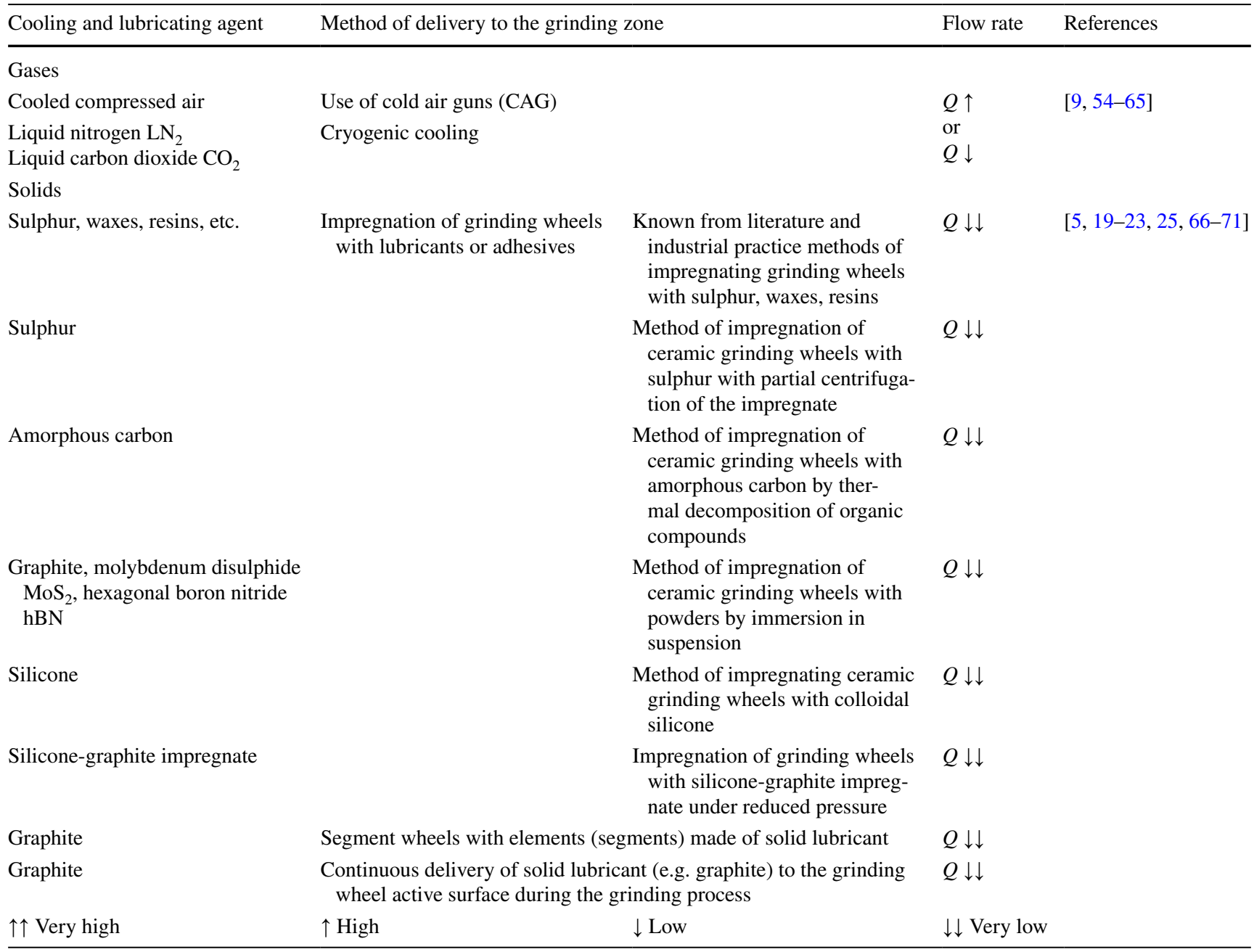

work of interdisciplinary teams integrating knowledge of grinding technology with knowledge of chemistry, material engineering, tribology as well as thermodynamics and heat transfer. The results of research on such teams should provide a basis for the widespread use of new coolants, lubricants and antiadhesives in grinding processes.

Particularly noteworthy is the growing importance of new numerical methods for solving complex fluid mechanics and heat exchange problems. The development of computational fluid dynamics (CFD) has enabled a broader understanding of the physical processes that occur during the flow of fluids both around and inside the modelled systems. Many of the most important aspects of fluid mechanics and heat transfer are of a non-linear nature, which makes it impossible to solve such problems analytically. The associated partial differential equations used in the CFD method, together with the ever-increasing computing power of computer systems, create unprecedented possibilities for analysing single- and multiphase flows in increasingly complex systems.

It should be expected that the growing public awareness of the protection of natural resources will in the future lead to an increasing pressure to find environmentally friendly machining methods, which, with regard to grinding processes, must result in a decisive reduction in the use of water-based oil emulsions and oils for cooling and lubrication of the grinding zone, which are commonly used today. Further legislative restrictions on the use of certain chemicals in manufacturing processes can also be expected to accelerate the spread of niche, in the current reality, hybrid cooling and lubrication methods. In this context, the hybrid methods presented in this paper are a real alternative to flooded cooling and can be improved and adapted to the requirements of specific technological operations of grinding in industrial conditions. 


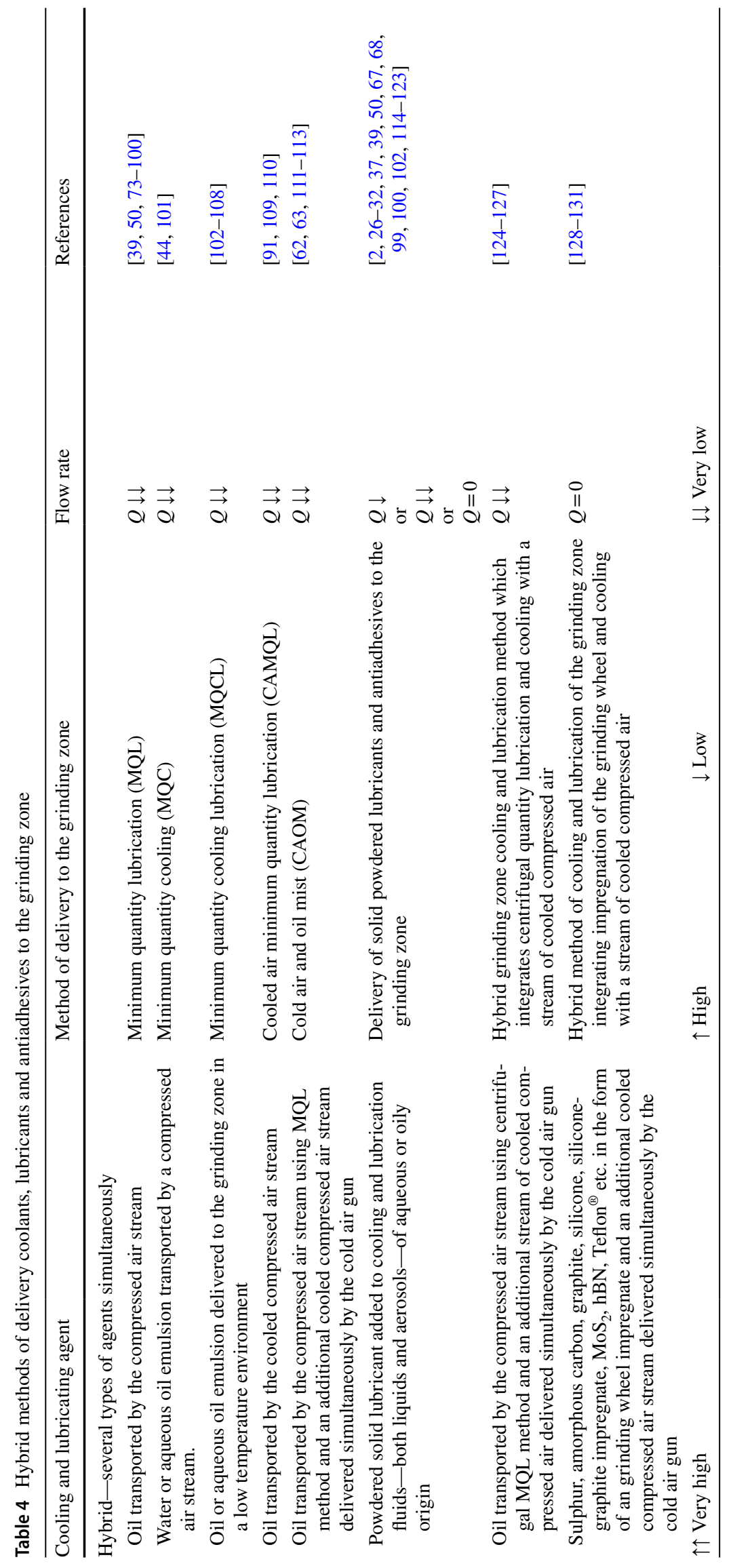


Funding Not applicable.

\section{Compliance with Ethical Standards}

Conflict of interest The authors declare that they have no conflict of interest.

Open Access This article is licensed under a Creative Commons Attribution 4.0 International License, which permits use, sharing, adaptation, distribution and reproduction in any medium or format, as long as you give appropriate credit to the original author(s) and the source, provide a link to the Creative Commons licence, and indicate if changes were made. The images or other third party material in this article are included in the article's Creative Commons licence, unless indicated otherwise in a credit line to the material. If material is not included in the article's Creative Commons licence and your intended use is not permitted by statutory regulation or exceeds the permitted use, you will need to obtain permission directly from the copyright holder. To view a copy of this licence, visit http://creativecommons.org/licenses/by/4.0/.

\section{References}

1. Marinescu, I. D., Rowe, W. B., Dimitrov, B., \& Inasaki, I. (2004). Tribology of abrasive machining processes. Norwich: William Andrew Publishing.

2. Shaji, S., \& Radhakrishnan, V. (2002). Investigations on the application of solid lubricants in grinding. Proceedings of the Institution of Mechanical Engineers, Part B: Journal of Engineering Manufacture, 216, 1325-1343.

3. Klocke, F. (2009). Manufacturing processes 2, grinding, honing, lapping. Berlin: Springer.

4. Shen, B., \& Shih, A. J. (2009). Minimum quantity lubrication (MQL) grinding using vitrified CBN wheels. Transactions of NAMRI/SME, 37, 129-136.

5. Marinescu, I. D., Hitchiner, M., Uhlmann, E., Rowe, W. B., \& Inasaki, I. (2007). Handbook of machining with grinding wheels. Boca Raton: CRC Press.

6. Brinksmeier, E., \& Walter, A. (2000). Generation of reaction layers on machined surfaces. Annals of the CIRP, 491, 435-438.

7. Peters, J., \& Atrens, S. (1976). An objective method for evaluating grinding coolants. Annals of the CIRP, 1, 247-250.

8. Venkata Rao, R. (2011). Advanced modeling and optimization of manufacturing processes: international research and development, Springer, London.

9. Manimaran, G., Pradeep, Kumar M., \& Venkatasamy, R. (2014). Influence of cryogenic cooling on surface grinding of stainless steel 316. Cryogenics, 59, 76-83.

10. Ahmed, L. S., Govindaraju, N., \& Kumar, M. P. (2016). Experimental investigations on cryogenic cooling in the drilling of titanium alloy. Materials and Manufacturing Processes, 31(5), 603-607.

11. Dhar, N. R., Kishore, N. S. V., Paul, S., \& Chattopadhyay, A. B. (2002). The effects of cryogenic cooling on chips and cutting forces in turning AISI 1040 and AISI 4320 steels. Proceedings of the Institution of Mechanical Engineers, Part B: Journal of Engineering Manufacture, 216(5), 713-724.

12. Cordes, S., Hübner, F., \& Schaarschmidt, T. (2014). Next generation high performance cutting by use of carbon dioxide as cryogenics. Procedia CIRP, 14, 401-405.

13. Gross, D., Heinz, A., Ebner, M., \& Hanenkamp, N. (2017). Assessment of process improvement potential of carbon dioxide as a cryogenic for machining operations. Applied Mechanics and Materials, 856, 151-158.

14. Jerold, B. D., \& Kumar, M. P. (2012). Machining of AISI 316 stainless steel under carbon-di-oxide cooling. Materials and Manufacturing Processes, 27(10), 1059-1065.

15. Patil, S., Pawar, P., Kekade, S., Patil, S., Gujar, K., \& Singh, R. K. P. (2016). Effect of gas based coolant lubricants on machinability of titanium alloy Ti6Al4V. Key Engineering Materials, 705, 233-239.

16. Garcia, E., Pombo, I., Sanchez, J. A., Ortega, N., Izquierdo, B., Plaza, S., et al. (2013). Reduction of oil and gas consumption in grinding technology using high pour-point lubricants. Journal of Cleaner Production, 51, 99-108.

17. Sanchez, J. A., Pombo, I., Alberdi, R., Izquierdo, B., Ortega, N., Plaza, S., et al. (2010). Machining evaluation of a hybrid MQL-CO ${ }_{2}$ grinding technology. Journal of Cleaner Production, 18(18), 1840-1849.

18. Howes, T. D. (1990). Assessment of the cooling and lubricative properties of grinding fluids. Annals of the CIRP, 39(1), 313-316.

19. Chirkov, G. V. (2007). Characteristics of the grinding wheel impregnation processes. Russian Engineering Research, 27(6), 387-389.

20. Gallagher T. P. (1967). Process for impregnating porous bodies with a solid fusible substance. US Patent No. 3341355, Patented 12.09.1967.

21. Harmann M. L. (1927). Abrasive article. US Patent No. 1615271, Patented 25.01.1927.

22. Jackson L. P. (1943). Filled abrasive article and filler for the same. US Patent No. 2333480, Patented 2.11.1943.

23. Jones, H. H. (1941). Composition for impregnating grinding wheels. US Patent No. 2240302, Patented 29.04.1941.

24. Saleem, M. Q., Ahmad, A. H., Raza, A., \& Qureshi, M. A. M. (2017). Air-assisted boric acid solid powder lubrication in surface grinding: an investigation into the effects of lubrication parameters on surface integrity of AISI 1045. International Journal of Advanced Manufacturing Technology, 91(9-12), 3561-3572.

25. Barros, N. G., da Silva, T., Canarim, R. C., de Aguiar, P. R., \& Bianchi, E. C. (2014). Utilization of teflon and aluminum oxide for wheel cleaning in minimum quantity lubrication (MQL) grinding. Materials Research, 17(1), 23-32.

26. Kalita, P., Malshe, A. P., Kumar, S. A., Yoganath, V. G., \& Gurumurthy, T. (2012). Study of specific energy and friction coefficent in minimum quantity lubrication grinding using oil-based nanolubricants. Journal of Manufacturing Processes, 14, 160-166.

27. Shen, B., Malshe, A. P., Kalita, P., \& Shih, A. J. (2008). Performance of novel $\mathrm{MoS}_{2}$ nanoparticles based grinding fluids in minimum quantity lubrication grinding. Transactions of NAMRI/ SME, 36, 357-364.

28. Sinha, M. K., Setti, D., Ghosh, S., \& Venkateswara, Rao P. (2016). An alternate method for optimisation of minimum quantity lubrication parameters in surface grinding. International Journal of Machining and Machinability of Materials, 18((56)), 586-605.

29. Wang, Y., Li, C., Zhang, Y., Yang, M., Li, B., Jia, D., et al. (2016). Experimental evaluation of the lubrication properties of the wheel/workpiece interface in MQL grinding with different types of vegetable oils. Journal of Cleaner Production, 127, 487-499.

30. Zhang, Y., Li, C., Jia, D., Li, B., Wang, Y., Yang, M., et al. (2016). Experimental study on effect of nanoparticle concentration on the lubricating roperty of nanofluids for MQL grinding of Ni-based alloy. Journal of Materials Processing Technology, 232, 100-115. 
31. Zhang, Y., Li, C., Jia, D., Zhang, D., \& Zhang, X. (2015). Experimental evaluation of the lubrication performance of $\mathrm{MoS}_{2} / \mathrm{CNT}$ nanofluid for minimal quantity lubrication in Ni-based alloy grinding. International Journal of Machine Tools and Manufacture, 99, 19-33.

32. Zhang, X., Li, C., Zhang, Y., Jia, D., Li, B., Wang, Y., et al. (2016). Performances of $\mathrm{Al}_{2} \mathrm{O}_{3} / \mathrm{SiC}$ hybrid nanofluids in minimum-quantity lubrication grinding. International Journal of Advanced Manufacturing Technology, 86, 3427-3441.

33. Kapłonek, K., Nadolny, K., Ungureanu, M., Pimenov, D. Y., \& Zieliński, B. (2019). SEM-based observations and analysis of the green silicon carbide ( $\mathrm{SiCg}$ ) grinding wheel active surfaces after the graphite and silicone impregnation process. International Journal of Surface Science and Engineering, 13(2-3), 181-200. https://doi.org/10.1504/ijsurfse.2019.102368.

34. Nadolny, K., Kapłonek, K., Niemczewska-Wójcik, M., \& Ungureanu, M. (2019). Microscopic analysis of the Sol-Gel alumina grinding wheel after the introduction of a synthetic organosilicon polymer-based impregnate dedicated for near dry grinding processes. International Journal of Surface Science and Engineering, 13(2-3), 110-132. https://doi.org/10.1504/ ijsurfse.2019.102361.

35. Kapłonek, W., Nadolny, K., Sutowska, M., Mia, M., Pimenov, D. Y., \& Gupta, M. K. (2019). Experimental studies on $\mathrm{MoS}_{2}$-treated grinding wheel active surface condition after high-efficiency internal cylindrical grinding process of INCONEL® alloy 718. Micromachines, 10(4), 255. https:// doi.org/10.3390/mi10040255.

36. Kapłonek, W., Nadolny, K., Rokosz, K., Marciano, J., Mia, M., Pimenov, D. Y., et al. (2020). Internal cylindrical grinding process of INCONEL ${ }^{\circledR}$ alloy 600 using grinding wheels with sol-gel alumina and a synthetic organosilicon polymer-based impregnate. Micromachines, 11, 115. https://doi.org/10.3390/ mi11020115.

37. Rabiei, F., Rahimi, A. R., Hadad, M. J., \& Saberi, A. (2017). Experimental evaluation of coolant-lubricant properties of nanofluids in ultrasonic assistant MQL grinding. International Journal of Advanced Manufacturing Technology, 93(9-12), 3935-3953.

38. Ravuri, B. P., Goriparthi, B. K., Revuru, R. S., \& Anne, V. G. (2016). Performance evaluation of grinding wheels impregnated with graphene nanoplatelets. International Journal of Advanced Manufacturing Technology, 85(9-12), 2235-2245.

39. Zhang, Y., Li, C., Jia, D., Zhang, D., \& Zhang, X. (2015). Experimental evaluation of $\mathrm{MoS}_{2}$ nanoparticles in jet MQL grinding with different types of vegetable oil as base oil. Journal of Cleaner Production, 87, 930-940.

40. Brinksmeier, E., Heinzel, C., \& Wittmann, M. (1999). Friction, cooling and lubrication in grinding. Annals of the CIRP, 48(2), 581-598.

41. Nguyen, T., \& Zhang, L. C. (2009). Performance of a new segmented grinding wheel system. International Journal of Machine Tools and Manufacture, 49(3-4), 291-296.

42. Tawakoli, T., Hadad, M., Sadeghi, M. H., Daneshi, A., \& Sadeghi, B. (2011). Minimum quantity lubrication in grinding: effects of abrasive and coolant-lubricant types. Journal of Cleaner Production, 19(17-18), 2088-2099.

43. Webster, J., Brinksmeier, E., Heinzel, C., Wittmann, M., \& Thoens, K. (2002). Assessment of grinding fluid effectiveness in continuous-dress creep feed grinding. Annals of the CIRP, 51(1), 235-240.

44. Weinert, K., Inasaki, I., Sutherland, J. W., \& Wakabayashi, T. (2004). Dry machining and minimum quantity lubrication. Annals of the CIRP, 53, 511-537.

45. Guitouni, A., Chaieb, I., Rhouma, A. B., \& Fredj, N. B. (2016). Effects of jet pressure on the ground surface quality and CBN wheel wear in grinding AISI 690 nickel-based superalloy. Journal of Materials Engineering and Performance, 25(11), 5055-5064.

46. Li, C., Zhang, X., Zhang, Q., Wang, S., Zhang, D., Jia, D., et al. (2014). Modeling and simulation of useful fluid flow rate in grinding. International Journal of Advanced Manufacturing Technology, 75(9-12), 1587-1604.

47. Vesali, A., \& Tawakoli, T. (2014). Study on hydrodynamic pressure in grinding contact zone considering grinding parameters and grinding wheel specifications. Procedia CIRP, 14, $13-18$.

48. Grindaix. (2020). Everything from a single professional sourcethe lubricoolant modular system from Grindaix! Electronic document: https://grindaix.de/en/coolant-products/. Accessed 12 June 2020 .

49. Nadolny, K. (2015). Small-dimensional sandwich grinding wheels with a centrifugal coolant provision system for traverse internal cylindrical grinding of steel 100Cr6. Journal of Cleaner Production, 93, 354-363. https://doi.org/10.1016/j.jclep ro.2015.01.046.

50. Oliveira, D. J., Guermandi, L. G., Bianchia, E. C., Diniz, A. E., Aguiar, P. R., \& Canarim, R. C. (2012). Improving minimum quantity lubrication in cBN grinding using compressed air. Journal of Materials Processing Technology, 212, 2559-2568.

51. Sieniawski, J., \& Nadolny, K. (2016). The effect upon grinding fluid demand and workpiece quality when an innovative zonal centrifugal provision method is implemented in the surface grinding of steel CrV12. Journal of Cleaner Production, 113, 960-972. https://doi.org/10.1016/j.jclepro.2015.11.017.

52. Sieniawski, J., \& Nadolny, K. (2016). Experimental study on grinding wheel radial wear in surface grinding of steel CrV12 using a zonal centrifugal coolant provision system. Proceedings of the Institution of Mechanical Engineers Part J: Journal of Engineering Tribology, 230(12), 1452-1461. https://doi. org/10.1177/1350650116637582.

53. Sieniawski, J., \& Nadolny, K. (2018). Experimental study into the grinding force in surface grinding of steel CrV12 utilizing a zonal centrifugal coolant provision system. Proceedings of the Institution of Mechanical Engineers Part B: Journal of Engineering Manufacture, 232(3), 394-403. https://doi.org/10.1177/09544 05416645256.

54. Wilczek, M., Bertling, J., \& Hintemann, D. (2004). Optimised technologies for cryogenic grinding. International Journal of Mineral Processing, 74(Supplement), S425-S434.

55. Chattopadhyay, A. B., Bose, A., \& Chattopadhyay, A. K. (1985). Improvements in grinding steels by cryogenic cooling. Precision Engineering, 7(2), 93-98.

56. Paul, S., Bandyopadhyah, P. P., \& Chattopadhyay, A. B. (1993). Effects of cryo-cooling in grinding steels. Journal of Materials Processing Technology, 37(1-4), 791-800.

57. Paul, S., \& Chattopadhyay, A. B. (1995). A study of effects of cryo-cooling in grinding. International Journal of Machine Tools and Manufacture, 35(1), 109-117.

58. Nguyen, T., Zarudi, I., \& Zhang, L. C. (2007). Grinding-hardening with liquid nitrogen: Mechanisms and technology. International Journal of Machine Tools and Manufacture, 47, 97-106.

59. Reddy, P. P., \& Ghosh, A. (2016). Some critical issues in cryogrinding by a vitrified bonded alumina wheel using liquid nitrogen jet. Journal of Materials Processing Technology, 229, 329-337.

60. Lee, P. H., \& Lee, S. W. (2011). Experimental characterization of micro-grinding process using compressed chilly air. International Journal of Machine Tools and Manufacture, 51(3), 201-209.

61. Liu, N. M., Chiang, K. T., \& Hung, C. M. (2013). Modeling and analyzing the effects of air-cooled turning on the machinability of 
Ti-6Al-4V titanium alloy using the cold air gun coolant system. International Journal of Advanced Manufacturing Technology, 67(5-8), 1053-1066.

62. Choi, H. Z., Lee, S. W., \& Jeong, H. D. (2002). The cooling effects of compressed cold air in cylindrical grinding with alumina and CBN wheels. Journal of Materials Processing Technology, 127(2), 155-158.

63. Nguyen, T., \& Zhang, L. C. (2003). An assessment of the applicability of cold air and oil mist in surface grinding. Journal of Materials Processing Technology, 140(1-3), 224-230.

64. Ramesh, K., Yeo, S. H., Zhong, Z. W., \& Huang, H. (2003). Ecological grinding with chilled air as coolant. Proceedings of the Institution of Mechanical Engineers, Part B: Journal of Engineering Manufacture, 217(3), 409-419.

65. Choi, H. Z., Lee, S. W., \& Jeong, H. D. (2001). A comparison of the cooling effects of compressed cold air and coolant for cylindrical grinding with a CBN wheel. Journal of Materials Processing Technology, 111(1-3), 265-268.

66. Saleem, M. Q., Ahmad, A. H., Raza, A., \& Qureshi, M. A. M. (2017). Air-assisted boric acid solid powder lubrication in surface grinding: An investigation into the effects of lubrication parameters on surface integrity of AISI 1045. International Journal of Advanced Manufacturing Technology, 91(9-12), 3561-3572.

67. Shaji, S., \& Radhakrishnan, V. (2002). An investigation on surface grinding using graphite as lubricant. International Journal of Machine Tools and Manufacture, 42, 733-740.

68. Shaji, S., \& Radhakrishnan, V. (2003). Analysis of process parameters in surface grinding with graphite as lubricant based on the Taguchi method. Journal of Materials Processing Technology, 141(1), 51-59.

69. Donachie, M. J., \& Donachie, S. J. (2002). Superalloys: A technical guide. Materials Park: ASM International.

70. Malkin, S., \& Guo, C. (2008). Grinding technology: Theory and applications of machining with abrasives. New York: Industrial Press Inc.

71. Mang, T., \& Dresel, W. (2007). Lubricants and lubrication. Veinheim: Wiley-VCH.

72. Klocke, F. (2011). Manufacturing processes 1: Cutting. Berlin: Springer.

73. Silva, L. R., Bianchi, E. C., Catai, R. E., Fusse, R. Y., França, T. V., \& Aguiar, P. R. (2005). Study on the behavior of the minimum quantity lubricant MQL-technique under different lubrication and cooling conditions when grinding ABNT 4340 steel. Journal of the Brazilian Society of Mechanical Sciences and Engineering, 27(2), 192-199.

74. Silva, L. R., Bianchi, E. C., Fusse, R. Y., Catai, R. E., Franca, T. V., \& Aguiar, P. R. (2007). Analysis of surface integrity for minimum quantity lubricant-MQL in grinding. International Journal of Machine Tools and Manufacture, 47(2), 412-418.

75. Tawakoli, T., Haddad, M. J., Sadeghi, M. H., Daneshi, A., Stockert, S., \& Rasifard, A. (2009). An experimental investigation of the effects of workpiece and grinding. International Journal of Machine Tools and Manufacture, 49(12-13), 924-932.

76. Barczak, L. M., Batako, A. D. L., \& Morgan, M. N. (2010). A study of plane surface grinding under minimum quantity lubrication (MQL) conditions. International Journal of Machine Tools and Manufacture, 50(11), 977-985.

77. Damasceno, R. F., de Souza Ruzzi, R., França, T. V., de Mello, H. J., da Silva, R. B., de Aguiar, P. R., et al. (2017). Performance evaluation of various cooling-lubrication techniques in grinding of hardened AISI 4340 steel with vitrified bonded CBN wheel. International Journal of Advanced Manufacturing Technology, 92(9-12), 3795-3806.
78. Hadad, M. J. (2015). An experimental investigation of the effects of machining parameters on environmentally friendly grinding process. Journal of Cleaner Production, 108, 217-231.

79. Morgan, M. N., Barczak, L., \& Batako, A. (2012). Temperatures in fine grinding with minimum quantity lubrication (MQL). International Journal of Advanced Manufacturing Technology, 60(9-12), 951-958.

80. Rowe, W. B., Morgan, M. M., Qi, H. S., \& Zheng, H. W. (1993). The effect of deformation on the contact area in grinding. Annals of the CIRP, 42, 409-412.

81. Simões, R. P., Bianchi, E. C., Oikawa, M. H., de Aguiar, P. R., Júnior, R. D., \& Canarim, R. C. (2014). Evaluation of different methods of cooling-lubrication in cylindrical grinding of advanced ceramic dip. Materials Research, 17(5), 1201-1212.

82. Wójcik, R., \& Nadolny, K. (2017). The effects of a variety of cutting fluids administered using the minimum quantity lubrication (MQL) method on the surface grinding process for nickel-based alloys. Journal of Zhejiang University Science A (Applied Physics \& Engineering), 18(9), 728-740. https://doi.org/10.1631/jzus. a1600416.

83. Batako, A. D. L., \& Tsiakoumis, V. (2015). An experimental investigation into resonance dry grinding of hardened steel and nickel alloys with element of MQL. International Journal of Advanced Manufacturing Technology, 77(1-4), 27-41.

84. Bianchi, E. C., Rodriguez, R. L., Hildebrandt, R. A., Lopes, J. C., de Mello, H. J., da Silva, R. B., et al. (2018). Plunge cylindrical grinding with the minimum quantity lubrication coolant technique assisted with wheel cleaning system. International Journal of Advanced Manufacturing Technology, 95(5-8), 2907-2916.

85. Bianchi, E. C., Sato, B. K., Sales, A. R., Lopes, J. C., de Mello, H. J., de Angelo Sanchez, L. E., et al. (2018). Evaluating the effect of the compressed air wheel cleaning in grinding the AISI 4340 steel with CBN and MQL with water. International Journal of Advanced Manufacturing Technology, 95(5-8), 2855-2864.

86. Chakule, R. R., Chaudhari, S. S., \& Talmale, P. S. (2017). Evaluation of the effects of machining parameters on MQL based surface grinding process using response surface methodology. Journal of Mechanical Science and Technology, 31(8), 3907-3916.

87. Hadad, M. J., \& Hadi, M. (2013). An investigation on surface grinding of hardened stainless steel S34700 and aluminum alloy AA6061 using minimum quantity of lubrication (MQL) technique. International Journal of Advanced Manufacturing Technology, 68(9-12), 2145-2158.

88. Huang, X., Ren, Y., Jiang, W., He, Z., \& Deng, Z. (2017). Investigation on grind-hardening annealed AISI5140 steel with minimal quantity lubrication. The International Journal of Advanced Manufacturing Technology, 89(1-4), 1069-1077.

89. Rabiei, F., Rahimi, A. R., Hadad, M. J., \& Ashrafijou, M. (2015). Performance improvement of minimum quantity lubrication (MQL) technique in surface grinding by modeling and optimization. Journal of Cleaner Production, 86, 447-460.

90. Sadeghi, M. H., Haddad, M. J., Tawakoli, T., \& Emami, M. (2009). Minimal quantity lubrication-MQL in grinding of Ti-6Al-4V titanium alloy. International Journal of Advanced Manufacturing Technology, 44(5-6), 487-500.

91. Tawakoli, T., Hadad, M. J., \& Sadeghi, M. H. (2010). Influence of oil mist parameters on minimum quantity lubrication-MQL grinding process. International Journal of Machine Tools and Manufacture, 50(6), 521-531.

92. Tawakoli, T., Hadad, M. J., \& Sadeghi, M. H. (2010). Investigation on minimum quantity lubricant-MQL grinding of 100Cr6 hardened steel using different abrasive and coolant-lubricant types. International Journal of Machine Tools and Manufacture, 50(8), 698-708.

93. Cetin, M. H., Ozcelik, B., Kuram, E., \& Demirbas, E. (2011). Evaluation of vegetable based cutting fluids with extreme 
pressure and cutting parameters in turning of AISI 304L by Taguchi method. Journal of Cleaner Production, 19(17-18), 2049-2056.

94. Pusavec, F., Krajnik, P., \& Kopac, J. (2010). Transitioning to sustainable production-Part I: Application on machining technologies. Journal of Cleaner Production, 18, 174-184.

95. Zhang, D., Li, C., Zhang, Y., Jia, D., \& Zhang, X. (2015). Experimental research on the energy ratio coefficient and specific grinding energy in nanoparticle jet MQL grinding. International Journal of Advanced Manufacturing Technology, 78(5-8), 1275-1288.

96. Stachurski, W., Sawicki, J., Krupanek, K., et al. (2020). Application of numerical simulation to determine ability of air used in MQL method to clean grinding wheel active surface during sharpening of hob cutters. International Journal of Precision Engineering and Manufacturing-Green Technology. https://doi. org/10.1007/s40684-020-00239-x.

97. Sen, B., Mia, M., Krolczyk, G. M., et al. (2019). Eco-friendly cutting fluids in minimum quantity lubrication assisted machining: A review on the perception of sustainable manufacturing. International Journal of Precision Engineering and Manufacturing-Green Technology. https://doi.org/10.1007/s40684-01900158-6.

98. Wang, Y., Li, C., Zhang, Y., et al. (2018). Processing characteristics of vegetable oil-based nanofluid MQL for grinding different workpiece materials. International Journal of Precision Engineering and Manufacturing-Green Technology, 5, 327-339. https://doi.org/10.1007/s40684-018-0035-4.

99. Hadad, M. J., \& Sharbati, A. (2016). Thermal aspects of environmentally friendly-MQL grinding process. Procedia CIRP, 40, $509-515$.

100. Li, C. H., Hou, Y. L., Xiu, S. C., \& Cai, G. Q. (2008). Application of lubrication theory to near dry-green grinding-feasibility analysis. Advanced Materials Research, 135(4), 44-46.

101. Priarone, P. C., Robiglio, M., Settineri, L., \& Tebaldo, V. (2015). Effectiveness of minimalizing cutting fluid use when turning difficult-to-cut alloys. Procedia CIRP, 29, 341-346.

102. Zhang, S., Li, J. F., \& Wang, Y. W. (2012). Tool life and cutting forces in end milling Inconel 718 under dry and minimum quantity cooling lubrication cutting conditions. Journal of Cleaner Production, 32, 81-87.

103. Maruda, R. W., Feldshtein, E., Legutko, S., \& Królczyk, G. M. (2016). Analysis of contact phenomena and heat exchange in the cutting zone under minimum quantity cooling lubrication conditions. Arabian Journal for Science and Engineering, 41, 661-668. https://doi.org/10.1007/s13369-015-1726-6.

104. Maruda, R. W., Krolczyk, G. M., Feldshtein, E., Szydlowski, M., Legutko, S., Pusavec, F., et al. (2016). A study on droplets sizes, their distribution and heat exchange for minimum quantity cooling lubrication (MQCL). International Journal of Machine Tools and Manufacture, 100, 81-92. https://doi.org/10.1016/j. ijmachtools.2015.10.008.

105. Maruda, R. W., Krolczyk, G. M., Michalski, M., Nieslony, P., \& Wojciechowski, S. (2017). Structural and microhardness changes after turning of the AISI 1045 steel for minimum quantity cooling lubrication. Journal of Materials Engineering and Performance, 26, 431-438. https://doi.org/10.1007/s1166 5-016-2450-4.

106. Ayoama, T. (2002). Development of a mixture supply system for machining with minimal quantity lubrication. Annals of the CIRP, 51(1), 289-292.

107. Machado, A. R., \& Wallbank, J. (1997). The effect of extremely low lubricant volumes in machining. Wear, 210(1-2), 76-82.

108. Chandrasekaran, H., \& Thuvander, A. (1998). Modelling tool stresses and temperature. Evaluation in turning using FEM. Machining Science and Technology, 2, 355-367.
109. Hadad, M. J., Tawakoli, T., Sadeghi, M. H., \& Sadeghi, B. (2012). Temperature and energy partition in minimum quantity lubrication-MQL grinding process. International Journal of Machine Tools and Manufacture, 54-55, 10-17.

110. Saberi, A., Rahimi, A. R., Parsa, H., Ashrafijou, M., \& Rabiei, F. (2016). Improvement of surface grinding process performance of CK45 soft steel by minimum quantity lubrication (MQL) technique using compressed cold air jet from vortex tube. Journal of Cleaner Production, 131, 728-738.

111. Yui A., Terashima M. (1999). Development of coolant-less grinding system. In Proceedings of the Thrid International Conference on Abrasive Technology (pp. 394).

112. Stachurski, W., Sawicki, J., Wójcik, R., \& Nadolny, K. (2018). Influence of application of hybrid MQL-CCA method of applying coolant during hob cutter sharpening on cutting blade surface condition. Journal of Cleaner Production, 171, 892-910. https:// doi.org/10.1016/j.jclepro.2017.10.059.

113. Stachurski, W., \& Nadolny, K. (2018). Influence of the condition of the surface layer of a hob cutter sharpened using the MQL-CCA hybrid method of coolant provision on its operational wear. International Journal of Advanced Manufacturing Technology, 98(5-8), 2185-2200. https://doi.org/10.1007/ s00170-018-2379-x.

114. Alberts, M., Kalaitzidou, K., \& Melkote, S. (2009). An investigation of graphite nanoplatelets as lubricant in grinding. International Journal of Machine Tools and Manufacture, 49(12-13), 966-970.

115. Irani, R. A., Bauer, R. J., \& Warkentin, A. (2005). A review of cutting fluid application in the grinding process. International Journal of Machine Tools and Manufacture, 45(15), $1696-1705$.

116. de Mello Belentani, R., Júnior, H. F., Canarim, R. C., Diniz, A. E., Hassui, A., Aguiar, P. R., et al. (2014). Utilization of minimum quantity lubrication (MQL) with water in CBN grinding of steel. Materials Research, 17(1), 88-96.

117. de Souza Ruzzi, R., de Mello Belentani, R., de Mello, H. J., Canarim, R. C., D’Addona, D. M., Diniz, A. E., et al. (2017). MQL with water in cylindrical plunge grinding of hardened steels using CBN wheels, with and without wheel cleaning by compressed air. International Journal of Advanced Manufacturing Technology, 90(1-4), 329-338.

118. Wojtewicz, M., Nadolny, K., Kapłonek, W., Rokosz, K., Matýsek, D., \& Ungureanu, M. (2019). Experimental studies using minimum quantity cooling (MQC) with molybdenum disulfide and graphite-based microfluids in grinding of INCONEL $®$ alloy 718. International Journal of Advanced Manufacturing Technology, 101(1-4), 637-661. https://doi.org/10.1007/s00170-018-2935-4.

119. Shaji, S., \& Radhakrishnan, V. (2003). An investigation on solid lubricant moulded grinding wheels. International Journal of Machine Tools and Manufacture, 43(9), 965-972.

120. Shaji, S., \& Radhakrishnan, V. (2003). Application of solid lubricants in grinding: Investigations on graphite sandwiched grinding wheels. Machining Science and Technology, 7(1), 137-155.

121. Tsai, M.-Y., \& Jian, S.-X. (2012). Development of a micro-graphite impregnated grinding wheel. International Journal of Machie Tools and Manufacture, 56, 94-101.

122. Mao, C., Tang, X., Zou, H., Huang, X., \& Zhou, Z. (2012). Investigation of grinding characteristic using nanofluid minimum quantity lubrication. International Journal of Precision Engineering and Manufacturing, 13(10), 1745-1752.

123. Lee, P. H., Lee, S. W., Lim, S. H., Lee, S. H., Ko, H. S., \& Shin, S. W. (2015). A study on thermal characteristics of micro-scale grinding process using nanofluid minimum quantity lubrication (MQL). International Journal of Precision Engineering and Manufacturing, 16(9), 1899-1909. 
124. Nadolny K., Wojtewicz M., Sienicki W. (2016). Abrasive tool for internal cylindrical grinding with delivery of cooling and lubricating agent. Polish patent no. PL 222732, 2016-02-10.

125. Kieraś, S., \& Nadolny, K. (2017). Overview of the centrifugal methods of provision the grinding fluid to the grinding zone. Journal of Mechanical and Energy Engineering, 1(1), 7-14.

126. Kieraś, S., Jakubowski, M., \& Nadolny, K. (2020). Simulation studies on centrifugal MQL-CCA method of applying coolant during internal cylindrical grinding process. Materials, 13, 2506. https://doi.org/10.3390/ma13112506.

127. Nadolny, K., \& Kieraś, S. (2020). Experimental studies on the centrifugal MQL-CCA method of applying coolant during the internal cylindrical grinding process. Materials, 13, 2383. https ://doi.org/10.3390/ma13102383.

128. Anderson, S., \& Malkin, R. B. (1974). Thermal aspects of grinding-part 1. Energy partitioning. Journal of Engineering for Industry, 96(4), 1177-1183.

129. Malkin, S., \& Guo, C. (2007). Thermal analysis of grinding. Annals of the CIRP, 56(2), 760-782.

130. Jin, T., \& Stephenson, D. J. (2008). A study of the convection heat transfer coefficients of grinding fluids. Annals of the CIRP, 57(1), 367-370.

131. Nadolny, K., \& Kieraś, S. (2020). New approach for cooling and lubrication in dry machining on the example of internal cylindrical grinding of bearing rings. Sustainable Materials and Technologies, 24, e00166. https://doi.org/10.1016/j.susmat.2020. e00166.

Publisher's Note Springer Nature remains neutral with regard to jurisdictional claims in published maps and institutional affiliations.

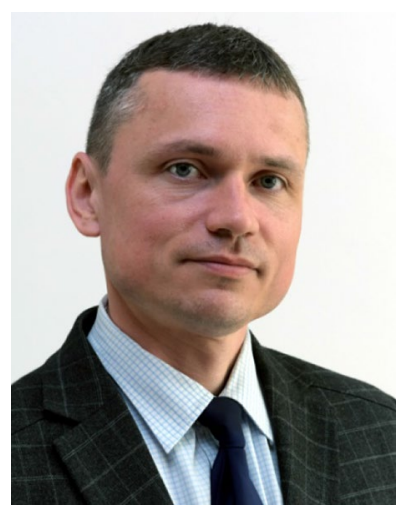

Krzysztof Nadolny received his M.Sc. degree in Mechanics and Machine Design and next the Ph.D (with honors) as well as D.Sc. degree in Machinery Construction and Operation from the Koszalin University of Technology, in 2001, 2006 and 2013, respectively. Since 2006, he has been a researcher in the Department of Production Engineering at the Koszalin University of Technology, where currently he works as a head of department. His scientific interests focus on problems concerning machining processes and tools, efficiency, monitoring and diagnostics of machining processes as well as tribology. He has participated in 2 international and 3 national research projects, presenting results of his work at 10 international and 21 national conferences, published more than 230 scientific papers in international and national journals, book chapters, as well as conference proceedings. He is also the author of 6 monographs and 13 national patents.

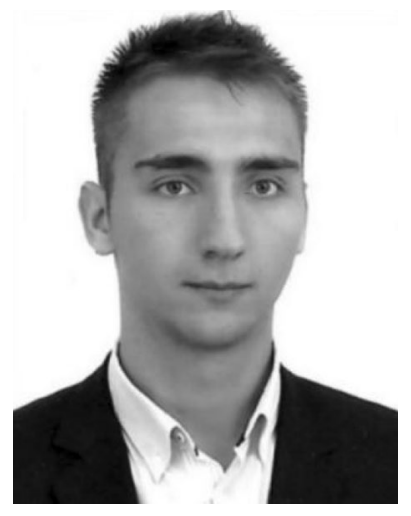

Seweryn Kieraś received his M.Sc. degree in Mechanics and Machine Design in 2014 and $\mathrm{Ph} . \mathrm{D}$ (with honors) in Machinery Construction and Operation from Koszalin University of Technology in 2019. He is engaged in research on minimizing the amount of coolant in grinding processes as a result of using hybrid methods of providing the coolant to grinding zone in the Department of Production Engineering at Koszalin University of Technology. He is the author of 1 monograph and over a dozen of scientific papers in national and international journals. He has presented results of his work on 1 international and 5 national conferences. Professionally he works as a hull designer in ship design office.

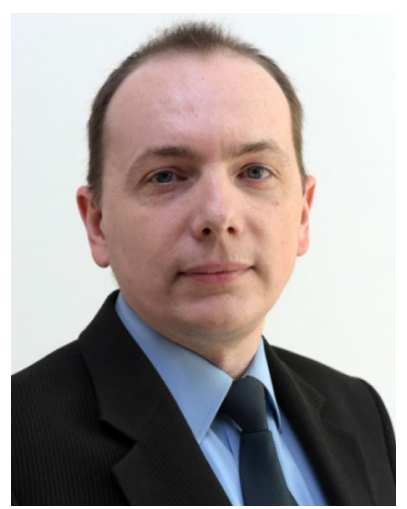

Paweł Sutowski received his MSc degree in Mechanics and Machine Design and PhD (with honors) as well as DSc degree in Machinery Construction and Operation from the Koszalin University of Technology in 2001, 2008 and 2020, respectively. Since 2008 he has didactic-research position in the Department of Production Engineering at the Koszalin University of Technology, where currently he works as Associate Professor as a member of a production planning and control team. His scientific work focus on problems concerning quality and efficiency control of machining processes by monitoring and diagnostic output signals. In his work, he uses modern signal acquire and converting unit systems. The most important in his work are non-destructive testing (NDT) methods with the use of acoustic signal and others. He has participated in national research projects, presenting results of his work at international and national conferences. He has published scientific papers in international and national journals, book chapters, as well as conference proceedings. He is also the co-author of one national patent. In his professional work he has also experience in domestic and foreign industry. He was a CAD designer (Satrorius AG, GIPO Corp.), as well as software programmer and commercialize (ZETO SA). 